\title{
Biomimetic Hybrid Membrane-Coated Xuetongsu Assisted with Laser Irradiation for Efficient Rheumatoid Arthritis Therapy Supporting Information
}

Huanghe $\mathrm{Yu}^{\dagger}$, Jialong Fan ${ }^{\dagger}$, Nuzhat Shehla ${ }^{\dagger}$, Yixing Qiu ${ }^{\dagger}$, Ye $\operatorname{Lin}^{\dagger}$, Zhou Wang ${ }^{\mathrm{b}}$, Liang $\mathrm{Cao}^{\dagger}$, Bin $\mathrm{Li}^{\dagger}$, Muhammad Daniyal ${ }^{\dagger}$, Yan $\mathrm{Qin}^{\dagger}$, Caiyun Peng ${ }^{\dagger}$, Xiong Cai ${ }^{\dagger}{ }^{* * *}$, Bin Liu ${ }^{\dagger * *}$ and Wei Wang ${ }^{\dagger *}$

$\dagger$ TCM and Ethnomedicine Innovation \& Development International Laboratory, Innovative Materia Medica Research Institute, School of Pharmacy, Hunan University of Chinese Medicine, Changsha, 410208, China.

\$College of Biology, Hunan University, Changsha, 410082, China.

\footnotetext{
* Corresponding author. TCM and Ethnomedicine Innovation \& Development International Laboratory, Innovative Materia Medica Research Institute, School of Pharmacy, Hunan University of Chinese Medicine, Changsha, 410208, China.

${ }^{* *}$ Corresponding author. College of Biology, Hunan University, Changsha, 410082, China.

***Corresponding author. Hunan University of Chinese Medicine, Changsha, 410208, China.

E-mail addresses:

wangwei402@hotmail.com (W.Wang);

binliu2001@hotmail.com (B. Liu);

caixiong@hnucm.edu.cn (X. Cai).
} 


\section{List of Supplementary Figures and Tables}

Figure S1. Anti-RA compounds 1-20 isolated from xuetong ...............................................

Figure S2. Anti-RA compounds 21-40 isolated from xuetong ............................................

Figure S3. Anti-RA compounds 41-60 isolated from xuetong .............................................

Figure S4. Anti-RA compounds $61-82$ isolated from xuetong ...........................................

Figure S5. The stem of Kadsura heteroclita (Roxb) Craib (Xuetong) and structure, monocrystalline

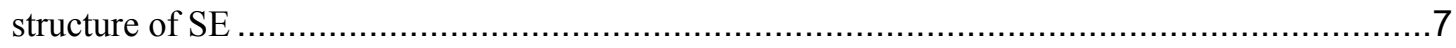

Figure S6. HPLC chromatograms and standard curve of SE ........................................

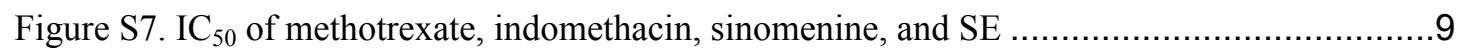

Figure S8. Fluorescence images of ROS production after treatment with HRPS NPs with $1.0 \mathrm{~W} / \mathrm{c}^{2}$

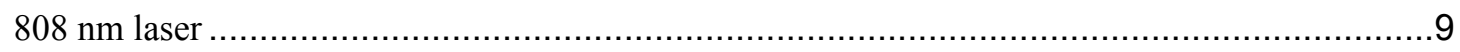

Figure S9. Immunofluorescence of the synovium of arthritic paws in different groups, mean

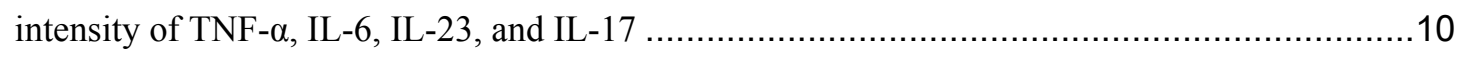

Figure S10. Blood routine examination of AIA rat blood treated with PBS, indomethacin, PB NPs,

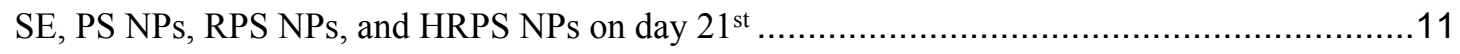

Figure S11. Blood routine examination of AIA rat blood treated with PBS, indomethacin, PB NPs,

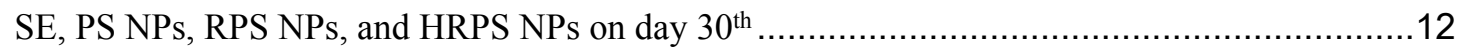

Figure S12. PCA analysis of the positive and negative iron mode between different groups .......15

Figure S13. Comparative metabolomics analysis determines the change in serum metabolites in

normal, model, SE treated and HRPS NPs treated groups................................................15

Figure S14. Regulation of genes and metabolites in signal transduction pathway in normal, model,

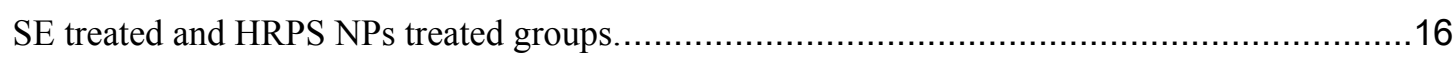


Figure S15. Hepatic and renal function tests of AIA rat blood after intravenous injection of PBS, indomethacin, PB NPs, SE, PS NPs, RPS NPs, and HRPS NPs with $808 \mathrm{~nm}$ laser for day $21^{\text {st }} \ldots 17$ Figure S16. Hepatic and renal function tests of AIA rat blood after intravenous injection of PBS, indomethacin, PB NPs, SE, PS NPs, RPS NPs, and HRPS NPs with $808 \mathrm{~nm}$ laser for day $21^{\text {st }} \ldots 18$

Figure S17. Biosafety assay of HRPS NPs in vivo. 19

Table S1. Anti-RA compounds isolated from xuetong 20

Table S2. Differential metabolites between model and normal groups, SE and model groups, HRPS NPs and model groups under positive and negative iron model.... .25

Method S1. HPLC condition .26

Method S2. Immunohistochemical and immunofluorescence assay .26

Method S3. Metabolite extraction and metabonomic analysis of serum .27 


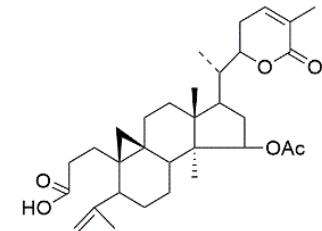

1

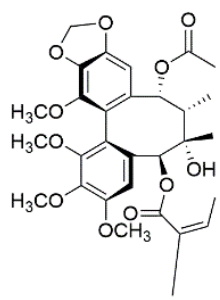

5
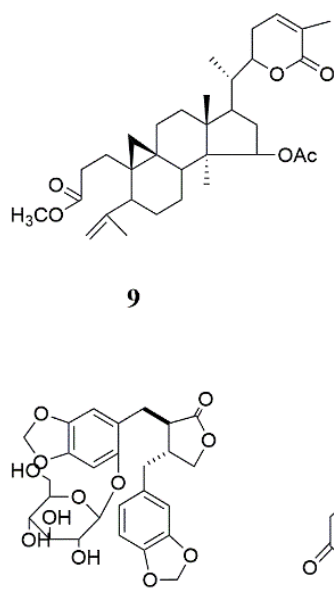

13<smiles>CC(=O)OC(C/C=C(/C)C(=O)O)C(C)C1CC[C@H]2C3CCC4C(C)(C)C(=O)CC[C@]45C[C@]35CC[C@]12C</smiles>

2

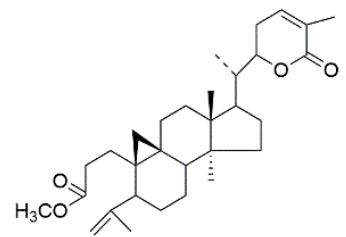

6<smiles>CC(C)=CCCC(C)C1CC[C@H]2C3CCC4C(C)(C)C(=O)CC[C@]4(C)[C@]3(C)CC[C@]12C</smiles>

3

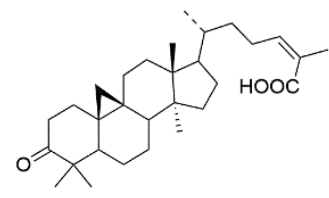

7

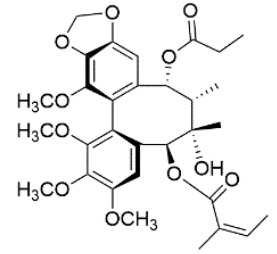

4<smiles>COc1cc(CC(C)C(C)Cc2ccc(O)c(OC)c2)ccc1O</smiles>

8

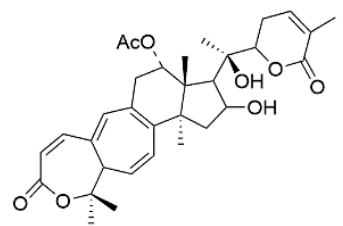

12

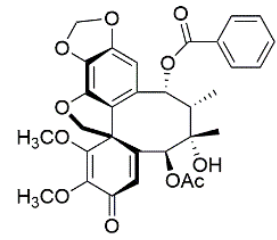

16

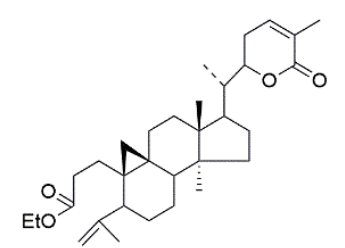

17

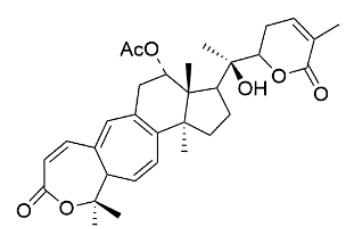

14

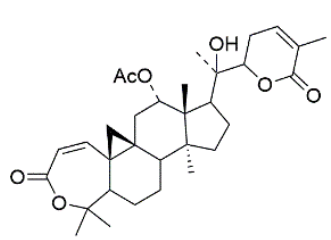

18

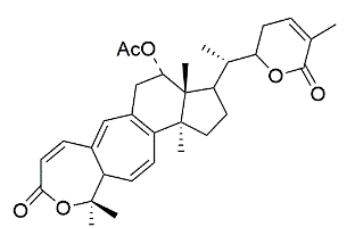

15

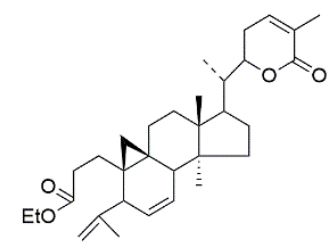

19

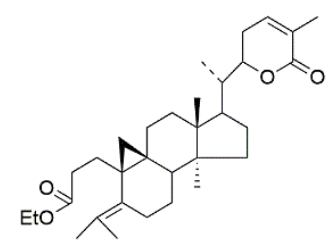

20

Figure S1 Anti-RA compounds 1-20 isolated from xuetong. 


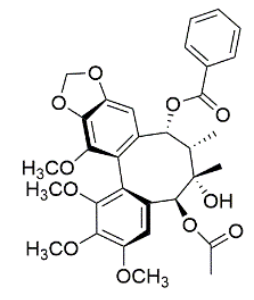

21

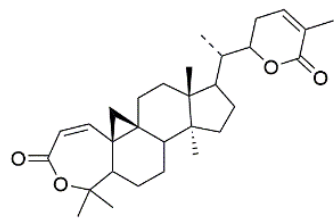

25<smiles></smiles>

29

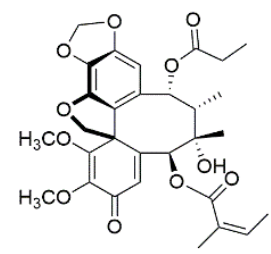

22

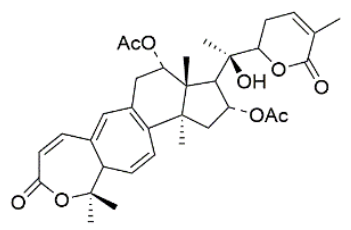

23

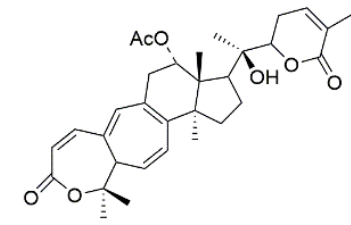

27

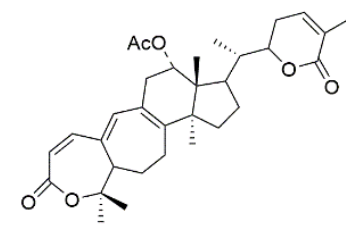

24

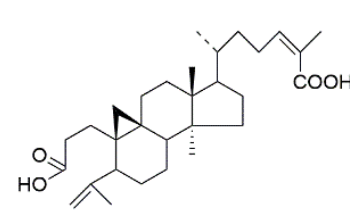

26

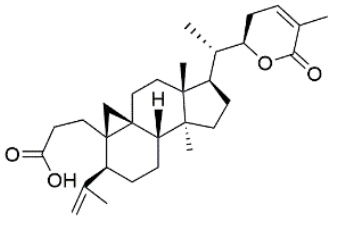

28

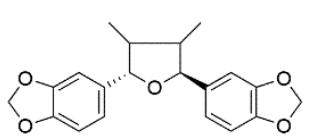

31

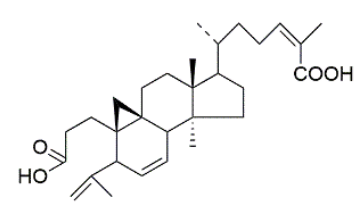

32

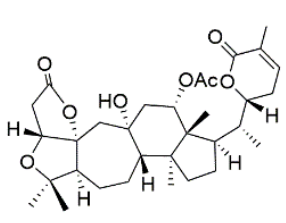

33

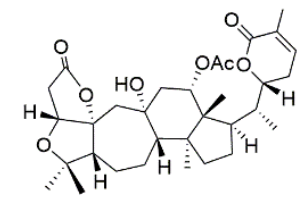

34

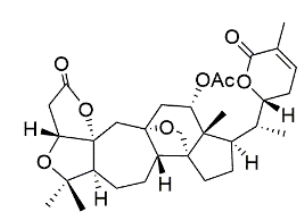

35

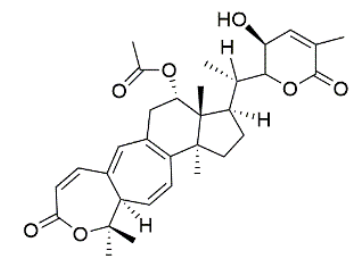

39

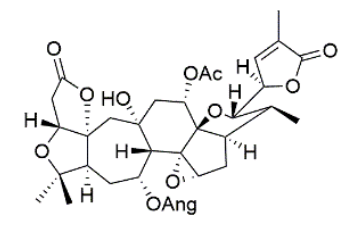

36

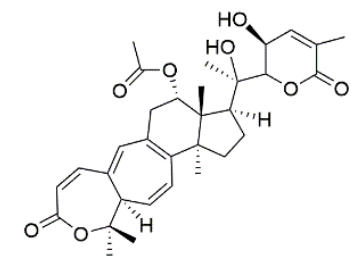

40

Figure S2 Anti-RA compounds 21-40 isolated from xuetong. 


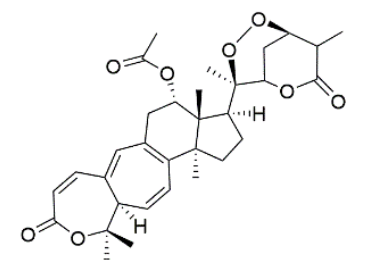

41

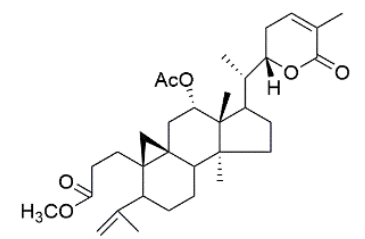

45

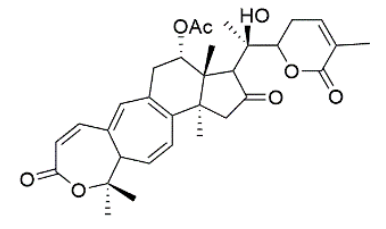

49<smiles>Cc1cc2c(cc1O)[C@@H](C)CC[C@@H]2C(C)(O)CO</smiles>

53

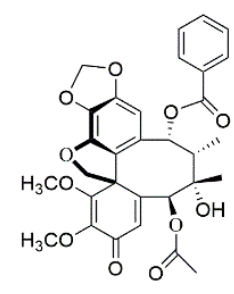

57

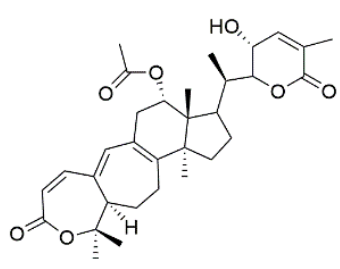

42

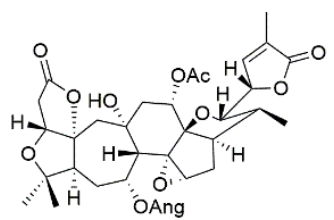

46

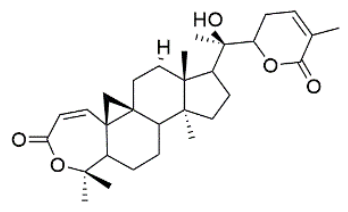

50

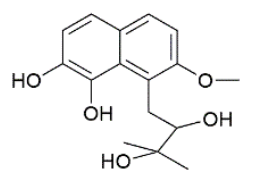

54<smiles>COc1cc([C@H]2c3cc(O)c(OC)cc3CC(CO)[C@H]2COC2OC(O)CC(O)C2O)ccc1O</smiles>

58

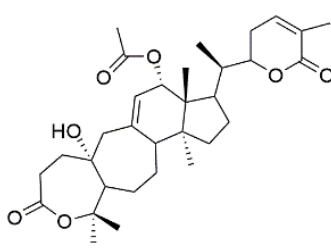

43

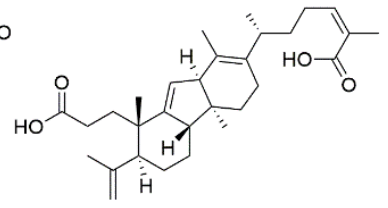

44

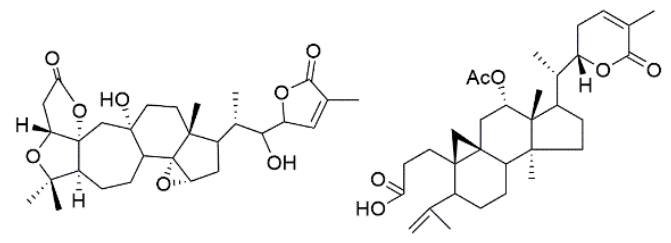

47

48

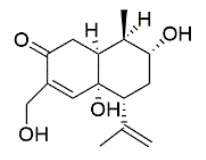

51

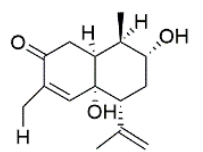

55

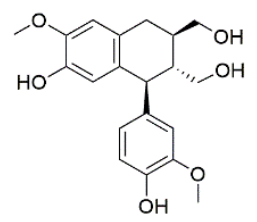

59

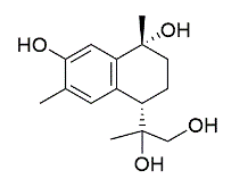

52

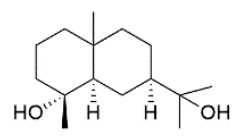

56

Figure S3 Anti-RA compounds 41-60 isolated from xuetong. 


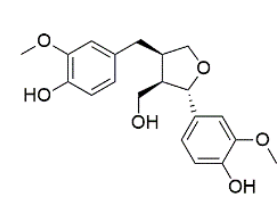

61

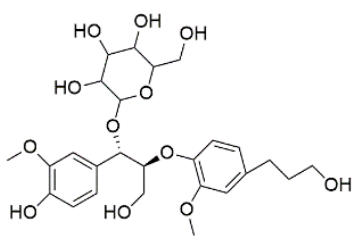

65

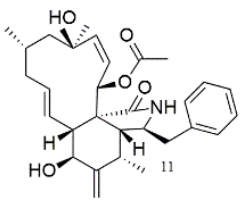

69

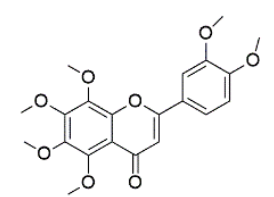

73

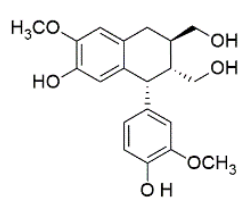

77

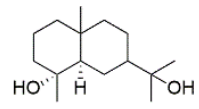

81

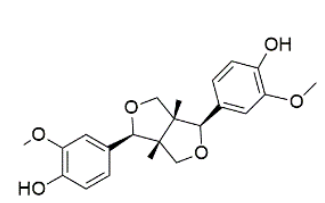

62

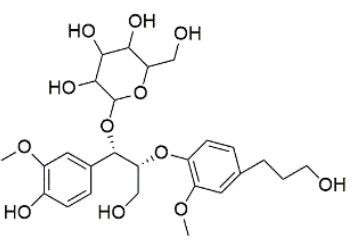

66

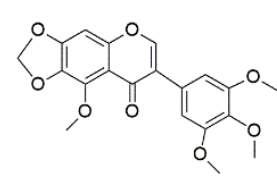

70

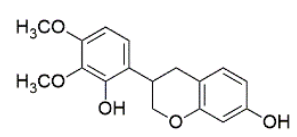

74

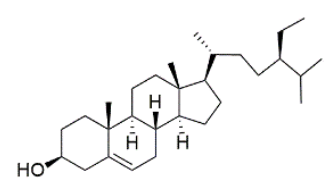

78

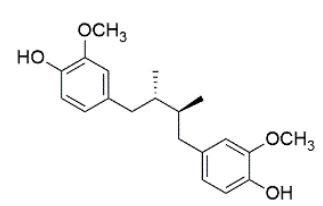

82

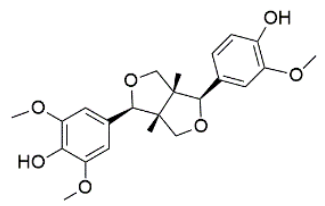

63

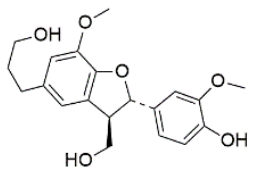

67<smiles>O=c1cc(-c2ccc(O)c(O)c2)oc2cc(O)cc(O)c12</smiles>

71<smiles>CC1CCC2(C)CCC3(C)C4CCC5C(C)(CCC(O)C5(C)C)C4=CCC3C2C1C</smiles>

75

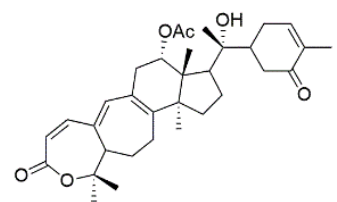

79

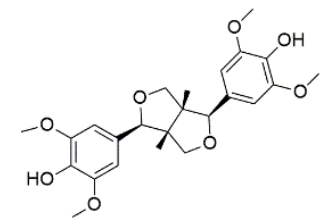

64

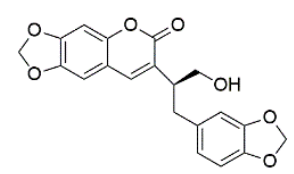

68

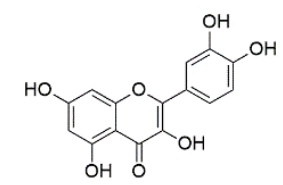

72

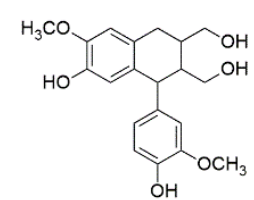

76

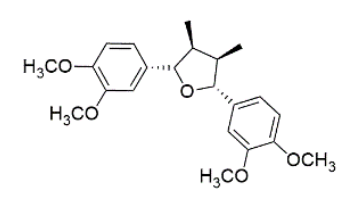

80

Figure S4 Anti-RA compounds 61-82 isolated from xuetong. 
A
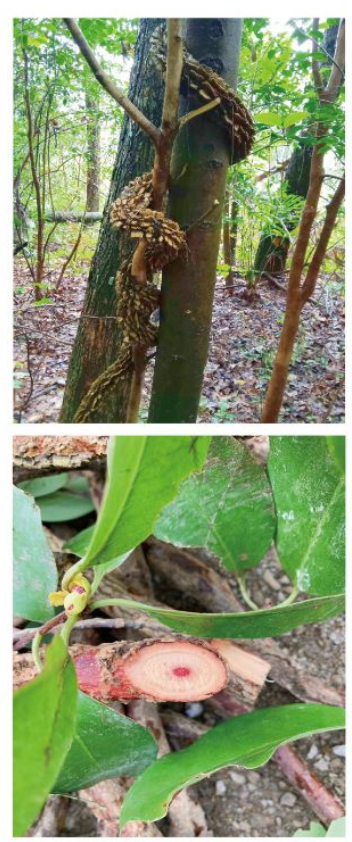

B
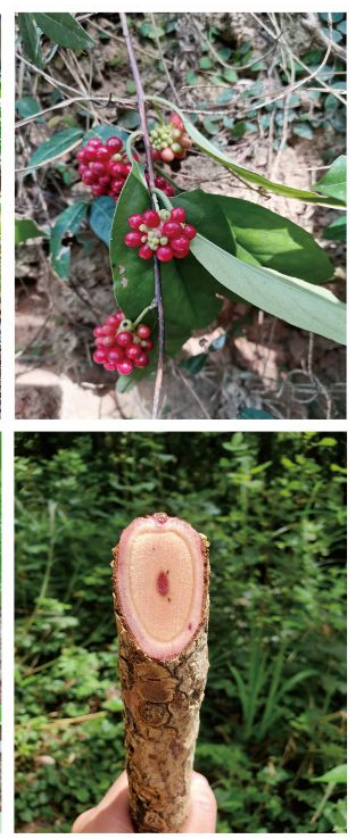

C
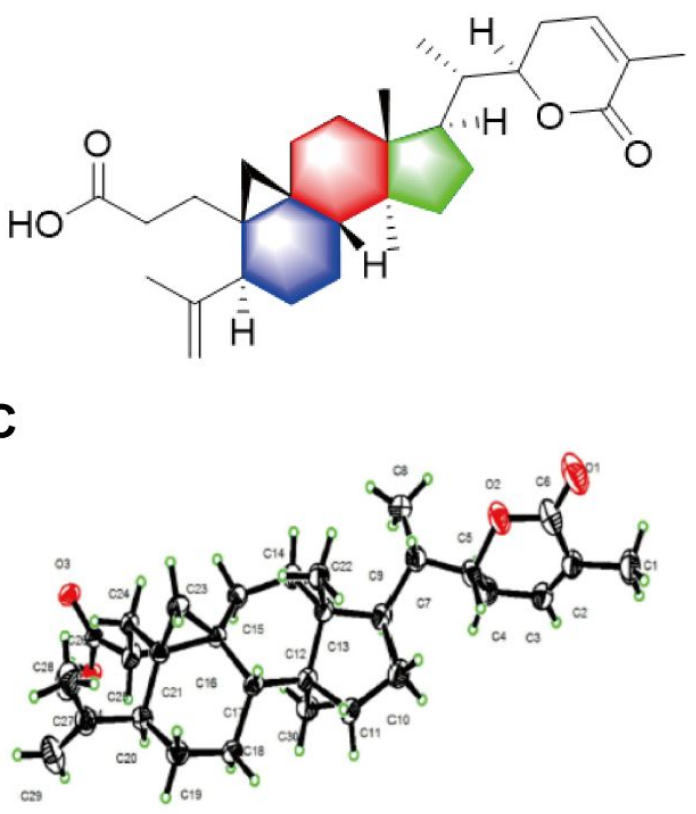

Figure S5 (A) The plant basic source of Kadsura heteroclita (Roxb) Craib (Xuetong). (B-C) The structure (B) and monocrystalline structure (C) of xuetongsu (SE).

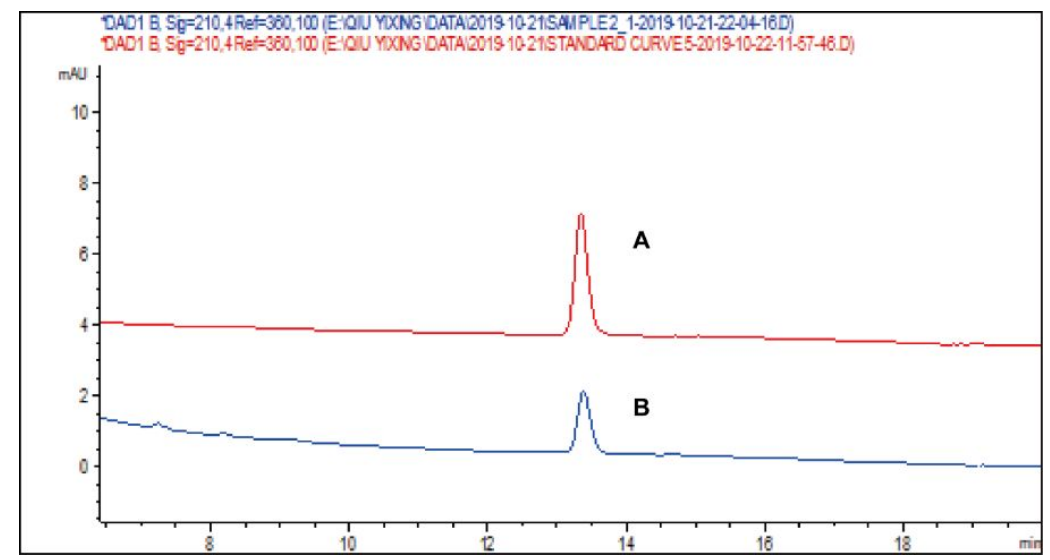




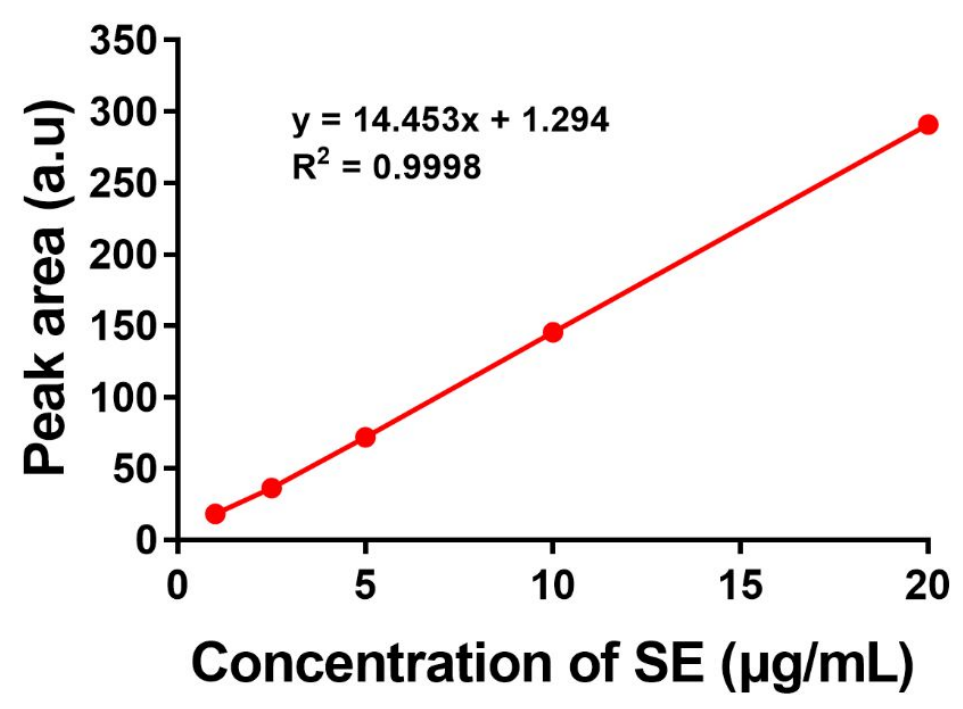

Figure S6 HPLC chromatograms and standard curve of SE.

The drug loading assay was performed under a different ratio of SE/PB. (A) Standard; (B) SE samples in PS NPs. To assure the loading efficiency, entrapment efficiency, and release of SE in PB NPs, the chromatographic fingerprint of SE was established and quantified using highperformance liquid chromatography (HPLC). The HPLC analysis was briefly performed on an Agilent 1260 system equipped with a G1311C quaternary pumps, a G1329B sampler, a G1316A column compartment and a G4212B diode-array detector. An Agilent TC-C18 $(5 \mu \mathrm{m}, 150 \mathrm{~mm} \times$ $4.6 \mathrm{~mm}$ ) column was applied for the determination of the SE constituents. The aqueous solution containing $0.1 \%$ phosphoric acid and $100 \%$ acetonitrile was used as the mobile phase. The gradient elution was as follows $0-30 \mathrm{~min}, 65-85 \%$ acetonitrile. The flow rate, column temperature, injection volume, and detection wavelength were optimized to be $1 \mathrm{~mL} \min ^{-1}, 25^{\circ} \mathrm{C}, 5 \mu \mathrm{L}$, and $210 \mathrm{~nm}$, respectively. Data acquisition was performed on Agilent Chem Station software. The correlation coefficient was $0.9998 \pm 0.0032$. The retention time of SE is $13.41 \mathrm{~min}$. 


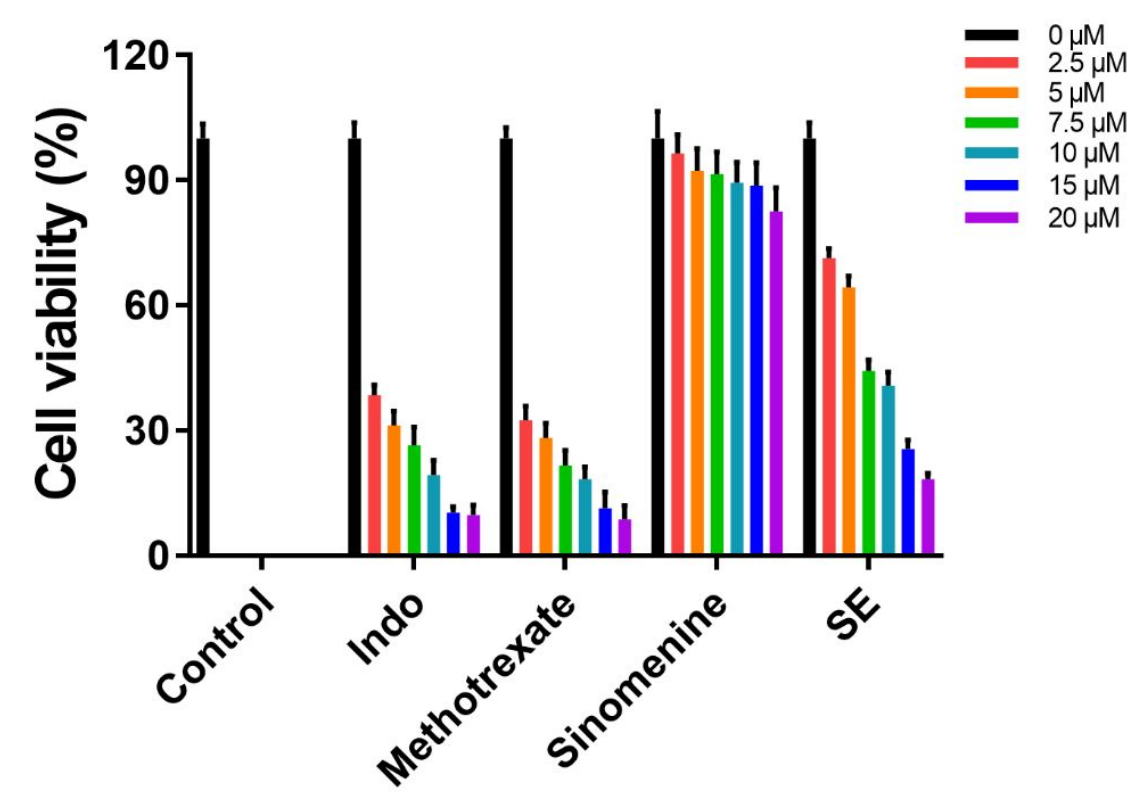

Figure $\mathrm{S} 7 \mathrm{IC}_{50}$ of methotrexate, indomethacin, sinomenine, and $\mathrm{SE}(\mathrm{n}=6)$.

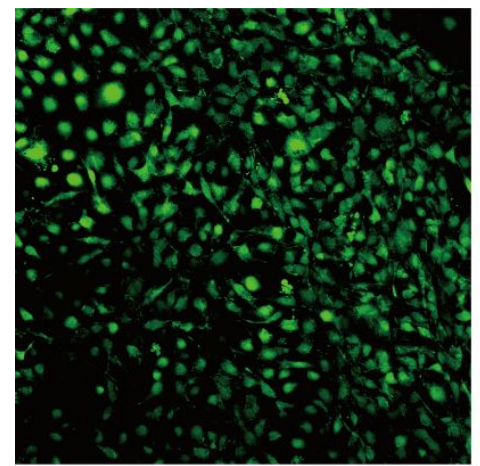

Control

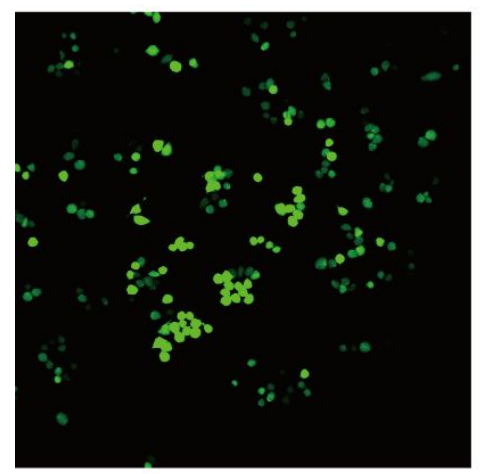

PB NPs+Laser

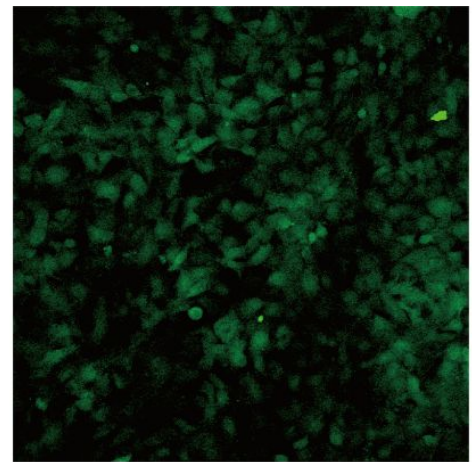

SE

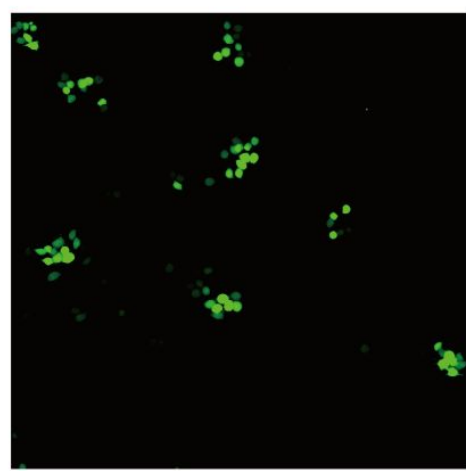

HRPS NPS

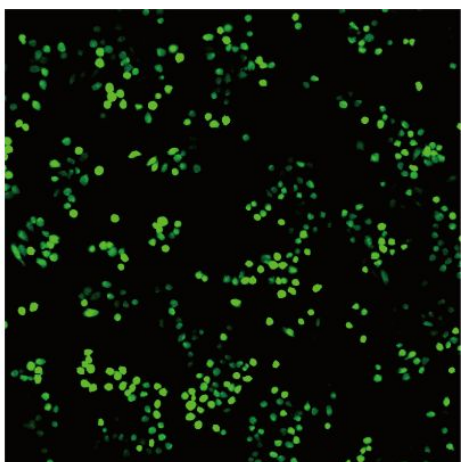

PB NPs

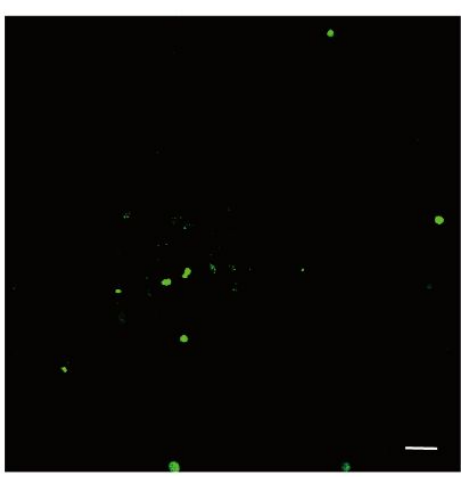

HRPS NPs + Laser

Figure S8 Fluorescence images of ROS production after treatment with HRPS NPs without/with

$1.0 \mathrm{~W} / \mathrm{cm}^{2} 808 \mathrm{~nm}$ laser for $5 \mathrm{~min}$. Scale bar, $100 \mu \mathrm{m}$. 
A
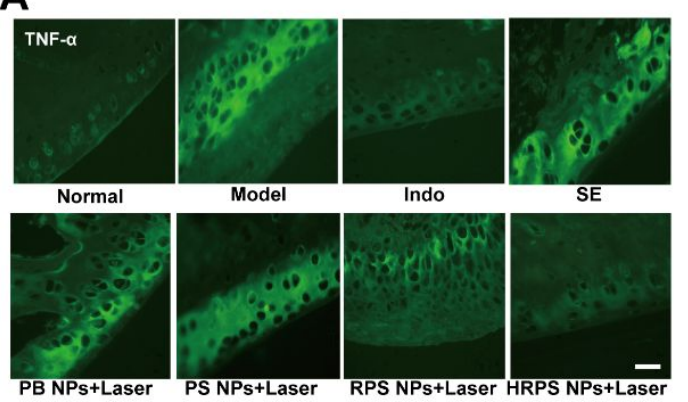

C

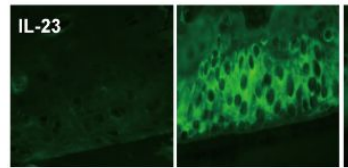

Normal

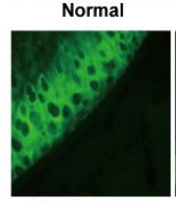

PB NPs+Laser

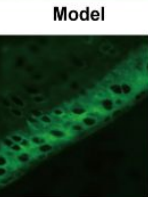

PS NPs+Laser

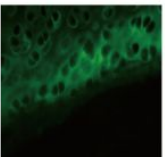

Indo

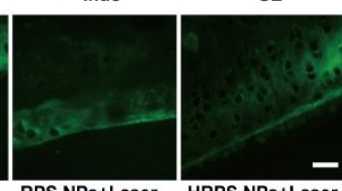

B
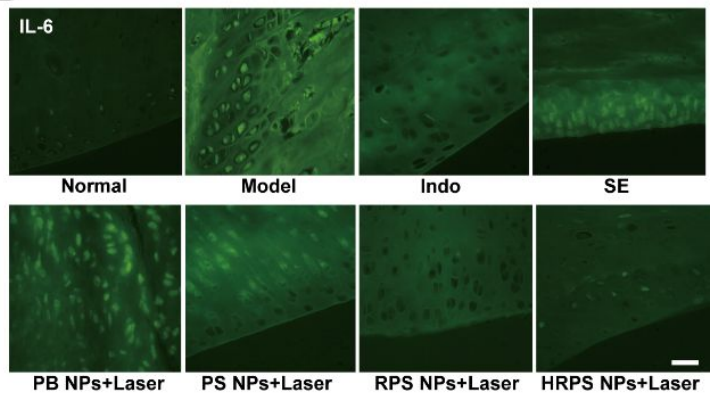

D
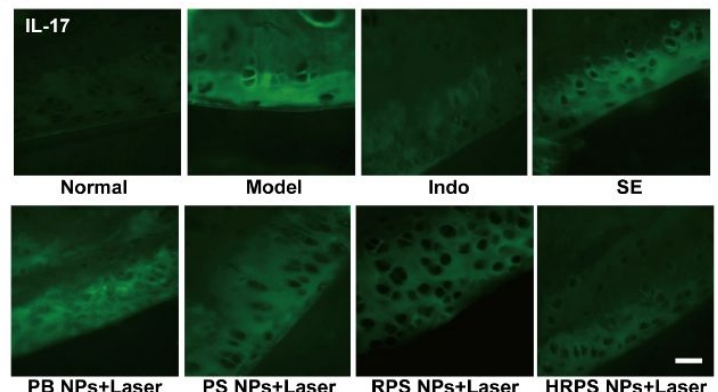

Figure S9 Immunofluorescence of the synovium of arthritic paws in different groups, mean intensity of TNF- $\alpha$, IL-6, IL-23, and IL-17. Immunofluorescence of the synovium of arthritic paws in different groups, mean intensity of TNF- $\alpha$ (A), IL-6 (B), IL-23 (C), and IL-17 (D). Scale bar, 100 $\mu \mathrm{m}(\mathrm{n}=6)$. 
A
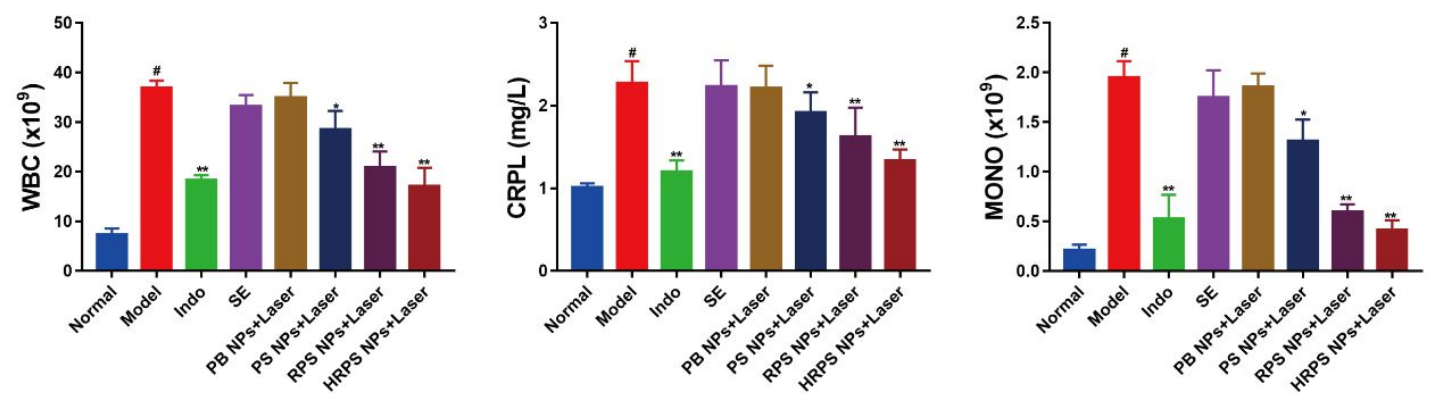

B
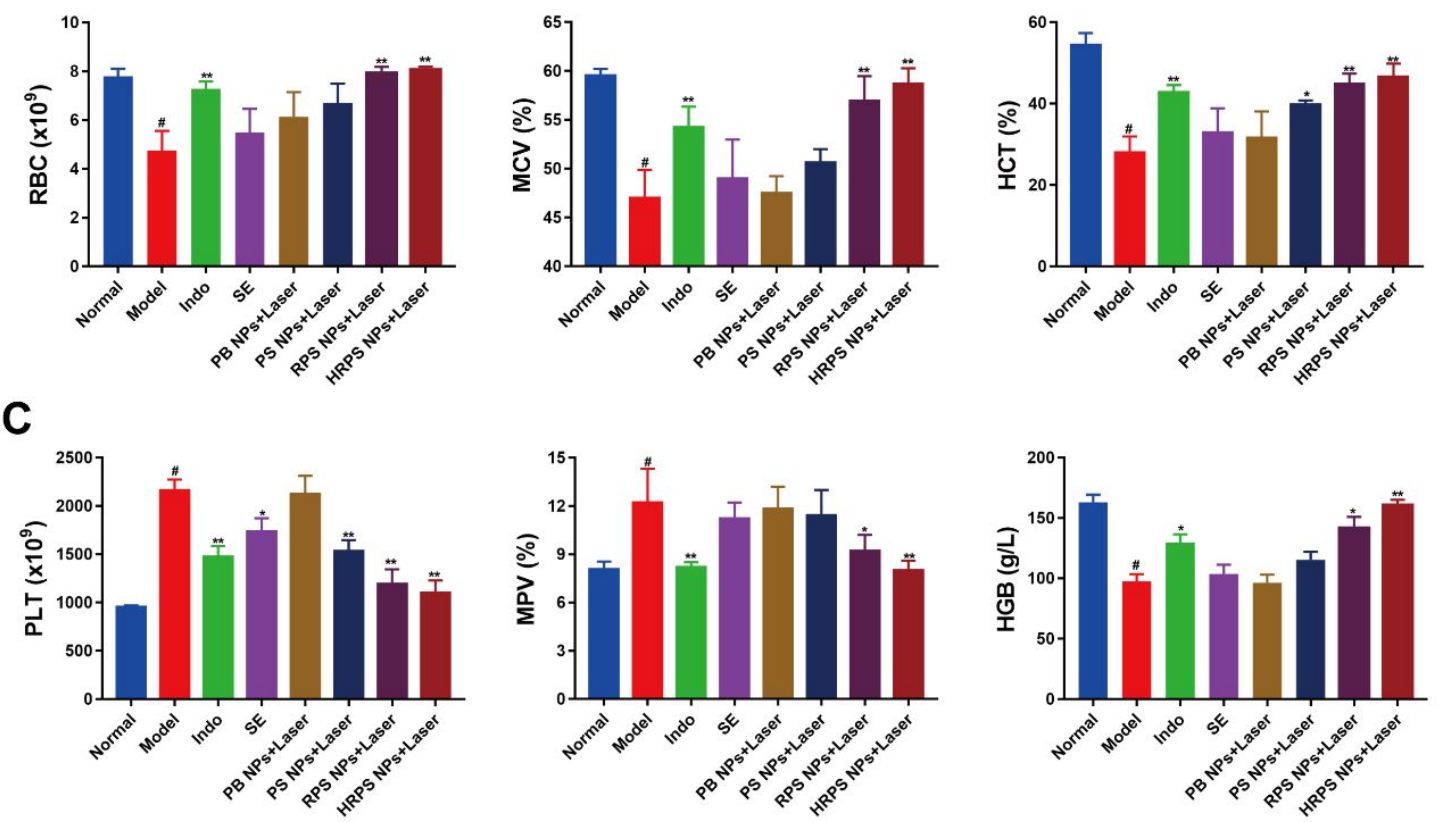

Figure S10 Blood routine examination of AIA rat blood treated with PBS, indomethacin, PB NPs,

SE, PS NPs, RPS NPs, and HRPS NPs on day $21^{\text {st }}$. (A) The WBC, CRPL, and MONO level of AIA rat blood treated with PBS, indomethacin, PB NPs, SE, PS NPs, RPS NPs, and HRPS NPs on day $21^{\text {st }} . \mathrm{n}=6$. (B) The RBC, MCV, and HCT level of AIA rat blood treated with PBS, indomethacin, PB NPs, SE, PS NPs, RPS NPs, and HRPS NPs with $808 \mathrm{~nm}$ laser on day $21^{\text {st }}\left(1.0 \mathrm{~W} / \mathrm{cm}^{2}\right) . \mathrm{n}=6$.

(C) The PLT, MPV, and HGB level of AIA rat blood treated with saline, indomethacin, PB NPs, SE, PS NPs, RPS NPs, and HRPS NPs with $808 \mathrm{~nm}$ laser on day $21^{\mathrm{st}}\left(1.0 \mathrm{~W} / \mathrm{cm}^{2}\right) . \mathrm{n}=6$. 
A
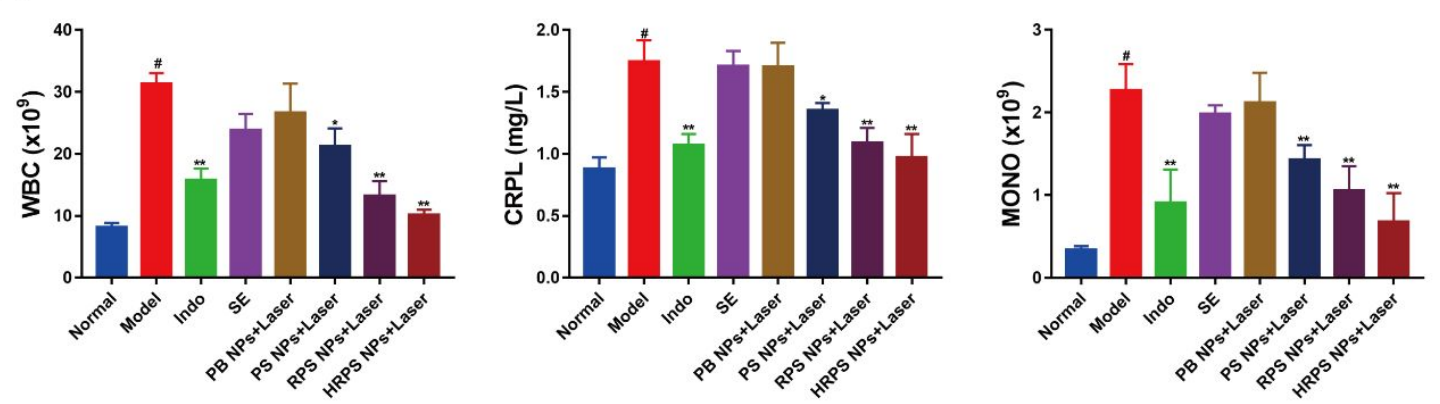

B
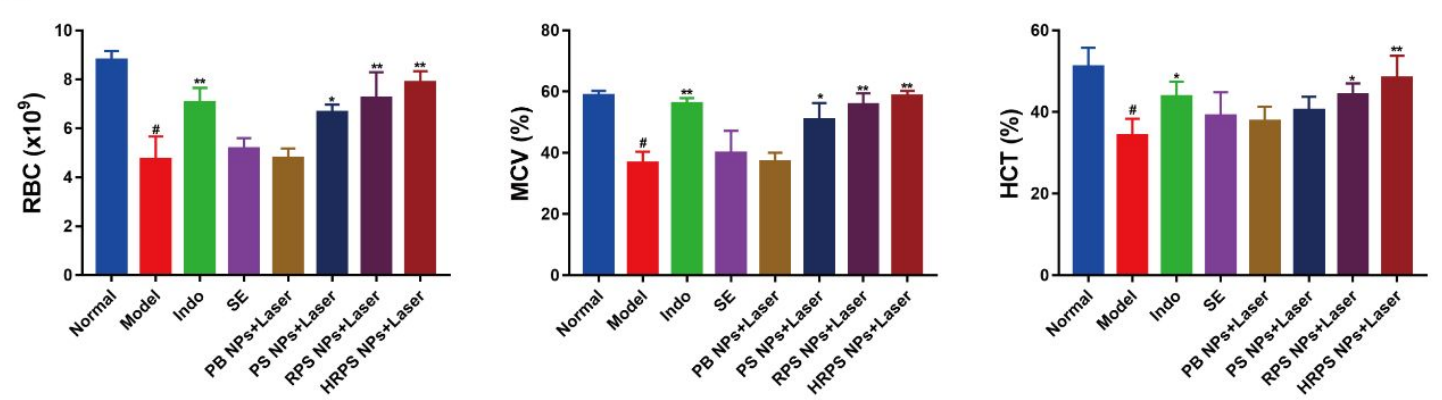

C
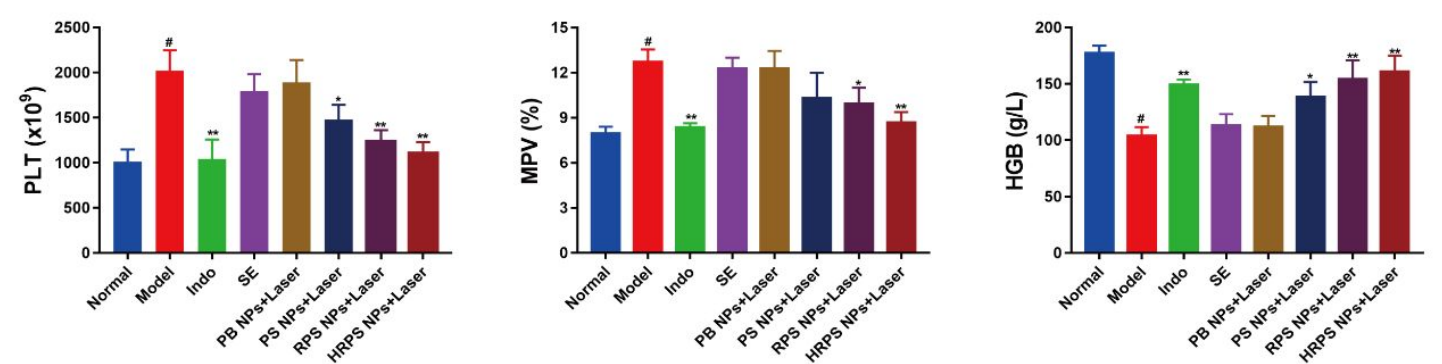

Figure S11 Blood routine examination of AIA rat blood treated with PBS, indomethacin, PB NPs,

SE, PS NPs, RPS NPs, and HRPS NPs on day $31^{\text {th }}$. (A) The WBC, CRPL, and MONO level of AIA rat blood treated with saline, indomethacin, PB NPs, SE, PS NPs, RPS NPs, and HRPS NPs on day $30^{\text {th }} . n=6$. (B) The RBC, MCV, and HCT level of AIA rat blood treated with saline, indomethacin, PB NPs, SE, PS NPs, RPS NPs, and HRPS NPs with $808 \mathrm{~nm}$ laser on day $30^{\text {th }}\left(1.0 \mathrm{~W} / \mathrm{cm}^{2}\right) . \mathrm{n}=6$.

(C) The PLT, MPV, and HGB level of AIA rat blood treated with saline, indomethacin, PB NPs, SE, PS NPs, RPS NPs, and HRPS NPs with $808 \mathrm{~nm}$ laser on day $30^{\text {th }}\left(1.0 \mathrm{~W} / \mathrm{cm}^{2}\right) . \mathrm{n}=6$. 
A

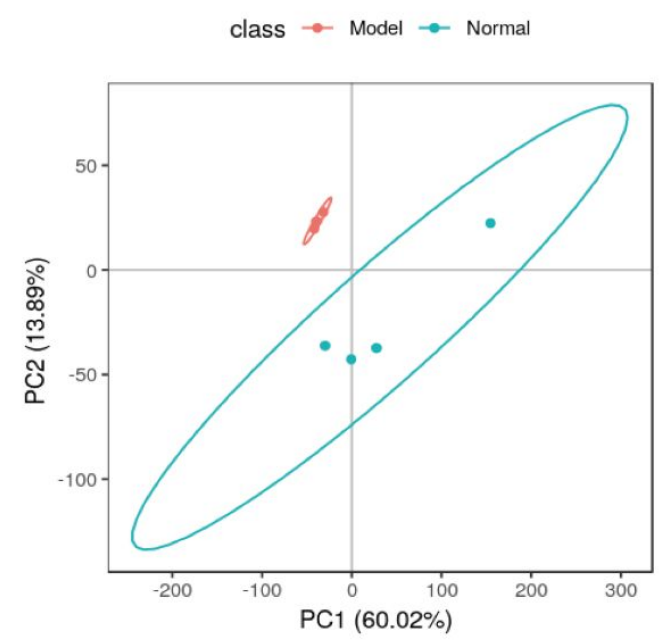

C

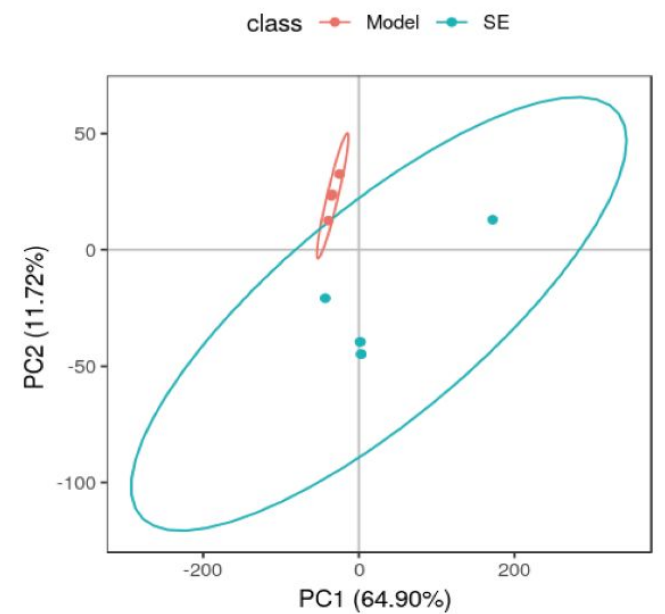

E

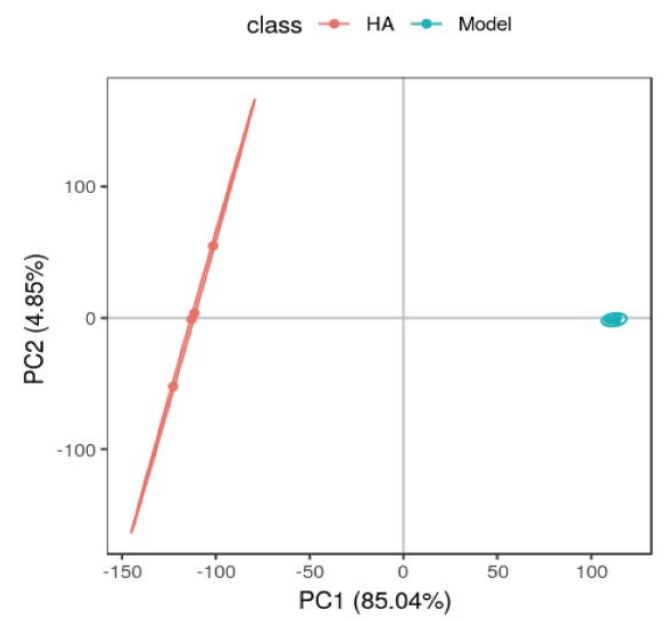

B

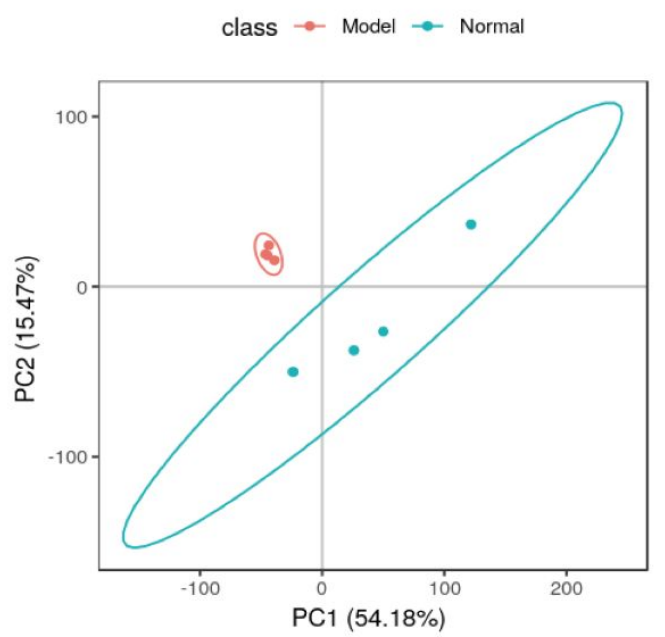

D

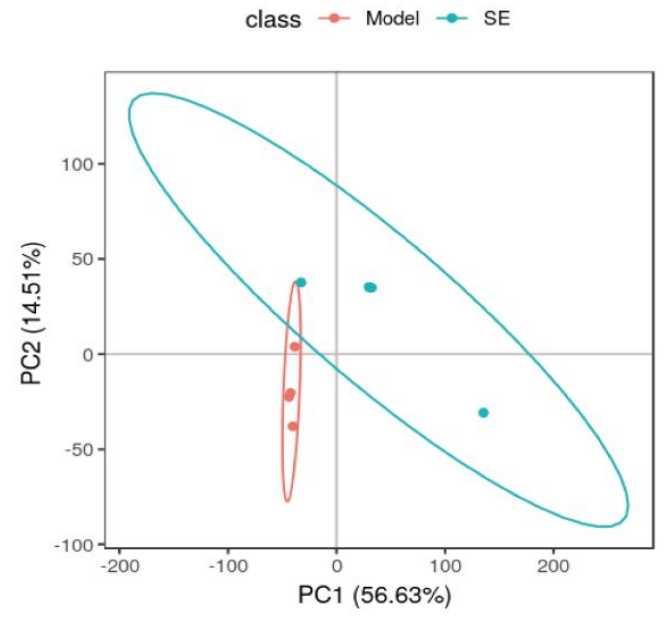

$\mathbf{F}$

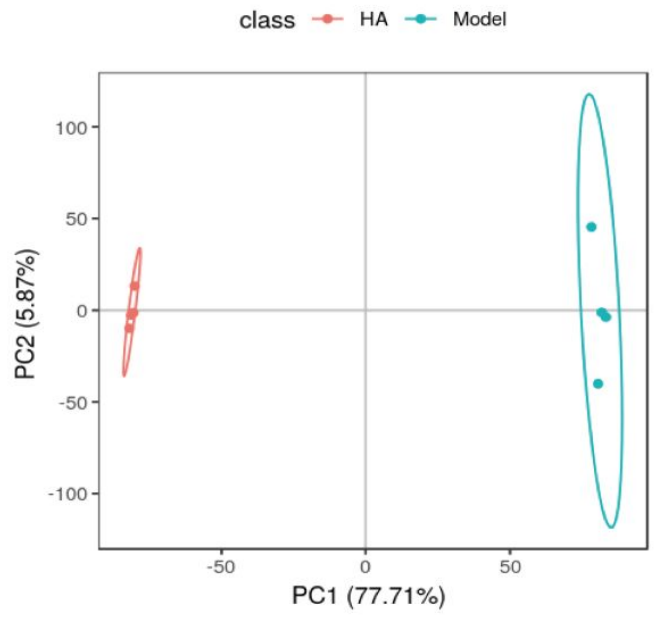

Figure S12 (A) PCA analysis of the positive iron mode between normal and model groups. (B) 
Negative iron mode between normal and model groups. (C) Positive iron mode between SE treated and model groups. (D) Negative iron mode between SE treated and model groups. (E) Positive iron mode between HRPS NPs (HA) treated and model groups. (F) Negative iron mode between HRPS NPs (HA) treated and model groups; 
A

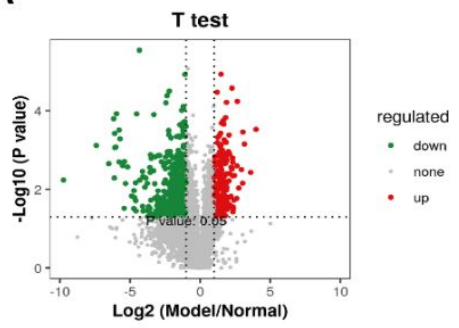

(1)

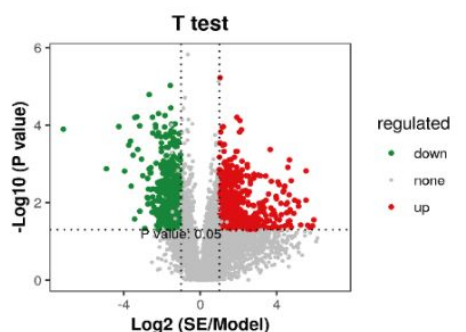

(4)

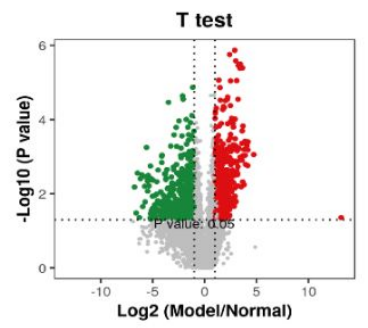

(2)

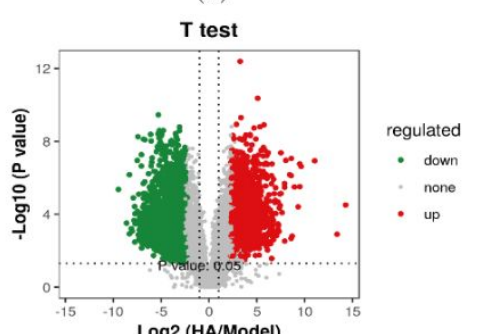

(5)

B

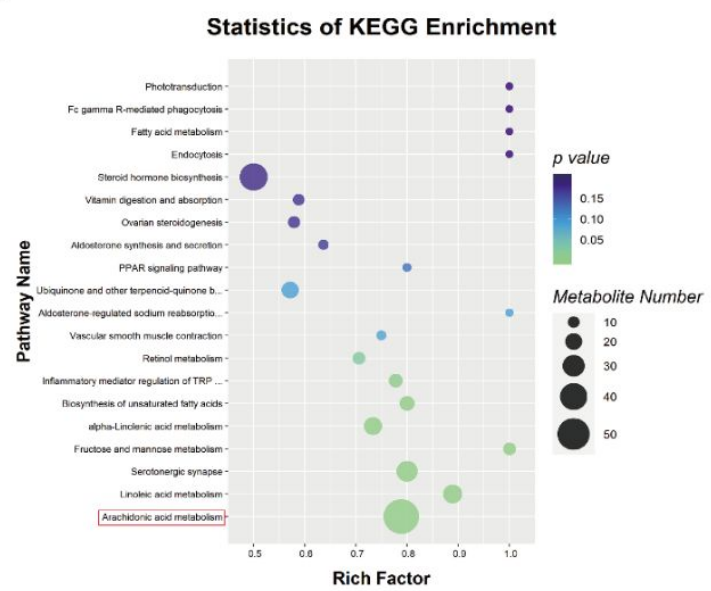

C
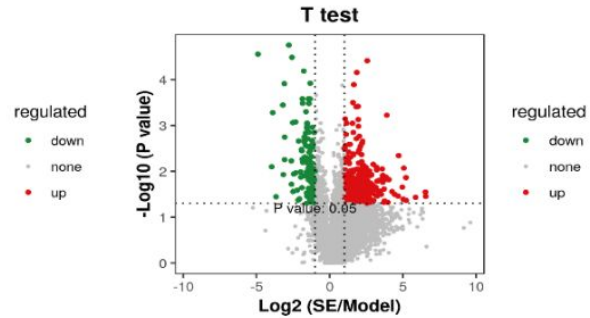

(3)

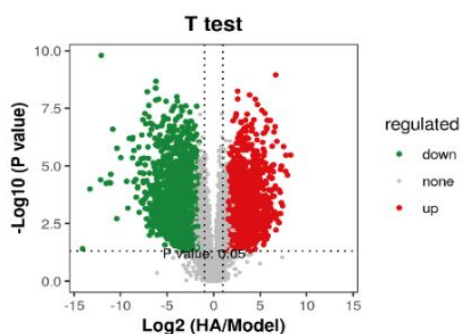

(6)

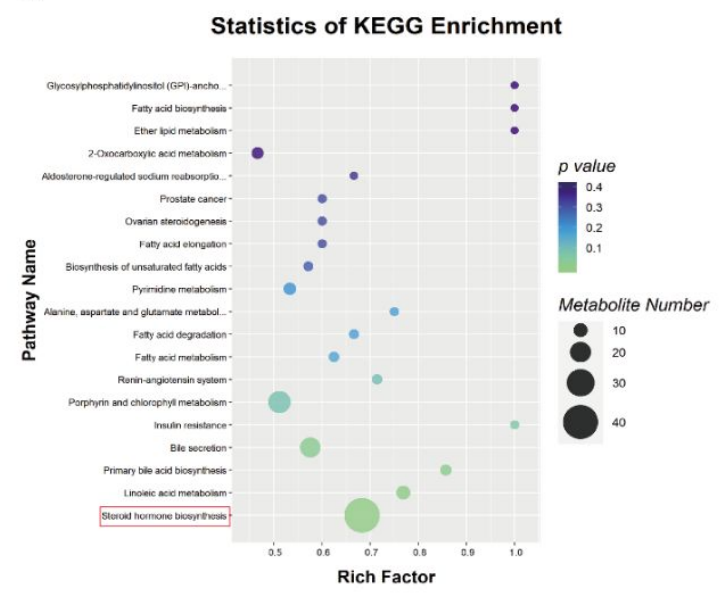

Figure S13 Comparative metabolomics analysis determines the change in serum metabolites in normal, model, SE treated and HRPS NPs treated groups. (A) (1) Volcano plot analysis of differential metabolites in normal group compared to model group under positive iron mode, (2) normal group compared to model group under negative iron mode, (3) SE treated group compared to model group under positive iron mode, (4) SE treated group compared to model group under negative iron mode, (5) HRPS NPs (HA) treated and model groups under positive iron mode, (6) HRPS NPs (HA) treated and model groups under negative iron mode. (B) KEGG pathway of differential metabolites in HRPS NPs (HA) treated and model groups under positive and negative iron modes. 
A

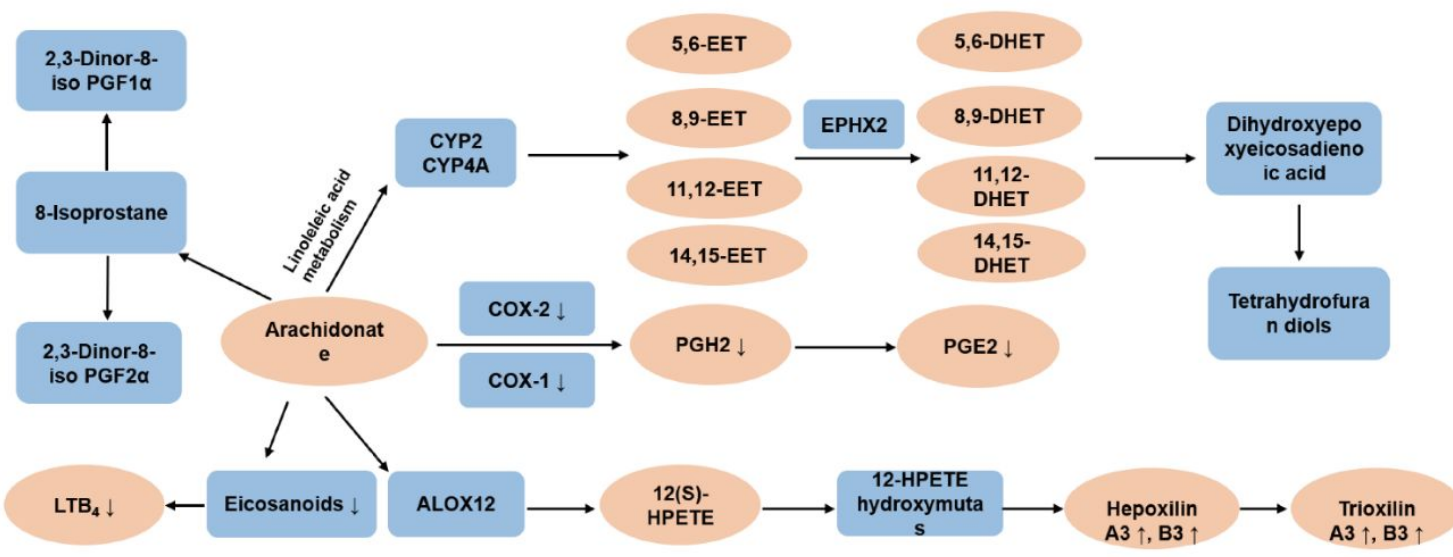

B

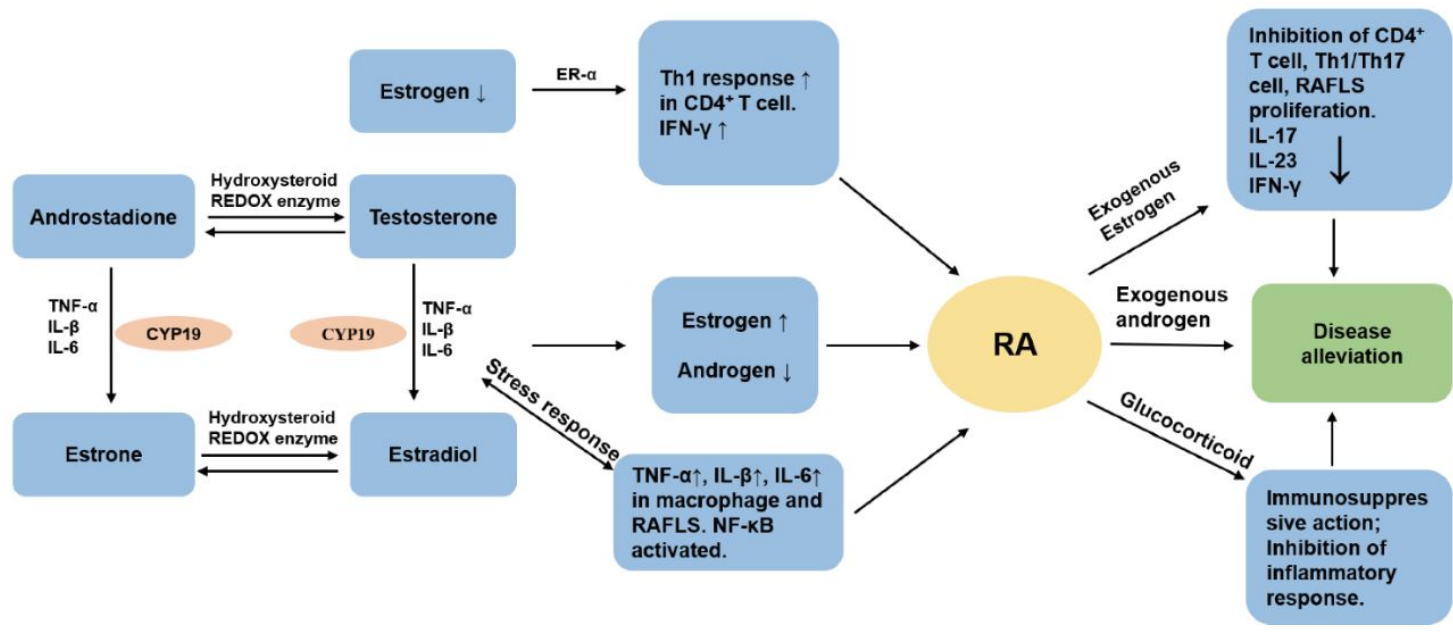

Figure S14 Regulation of genes and metabolites in signal transduction pathway in normal, model,

SE treated and HRPS NPs treated groups. (A) Arachidonic acid metabolism - reference pathway in RA. (B) Steroid hormone biosynthesis pathway in RA. 
A

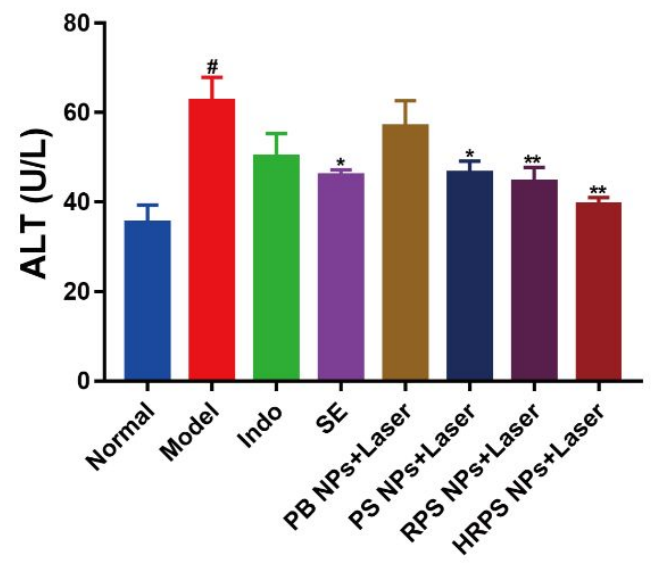

C

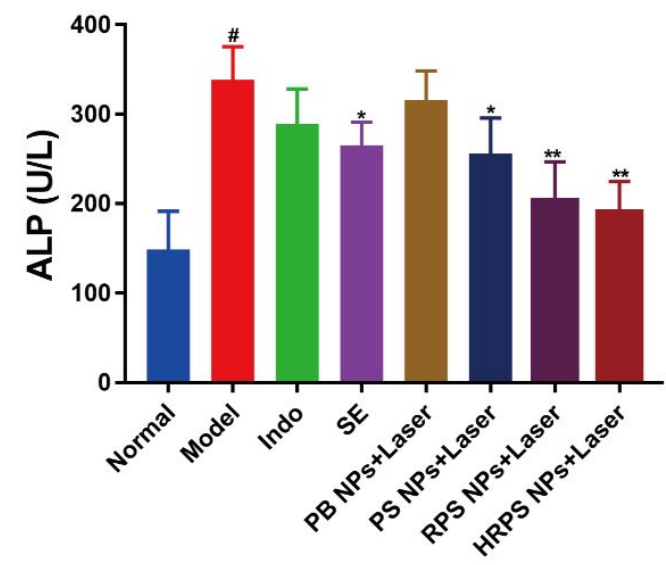

B

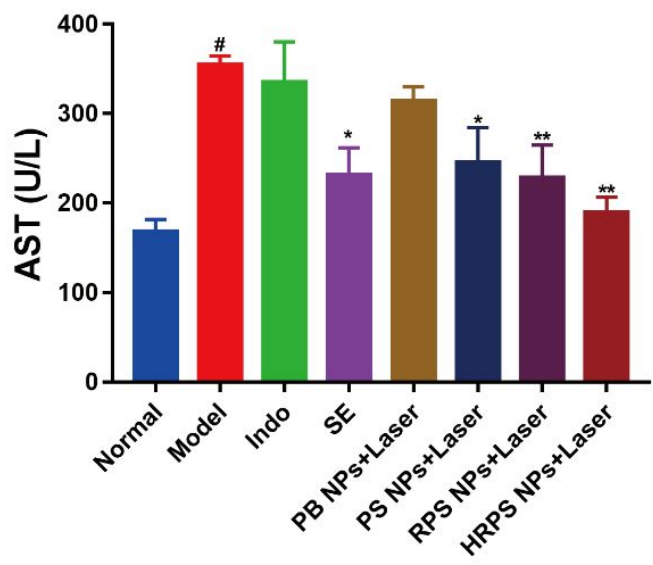

D

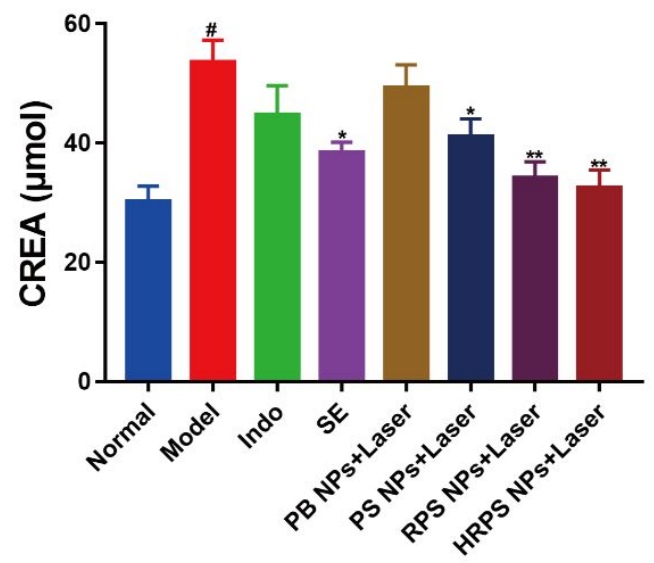

Figure S15 Hepatic and renal function tests of ALT (A), AST (B), ALP (C), CREA (D) in AIA rat blood after intravenous injection of saline, indomethacin, PB NPs, SE, PS NPs, RPS NPs, and HRPS NPs with $808 \mathrm{~nm}$ laser for day $21^{\mathrm{st}}\left(1.0 \mathrm{~W} / \mathrm{cm}^{2}\right) \mathrm{n}=6$. 
A

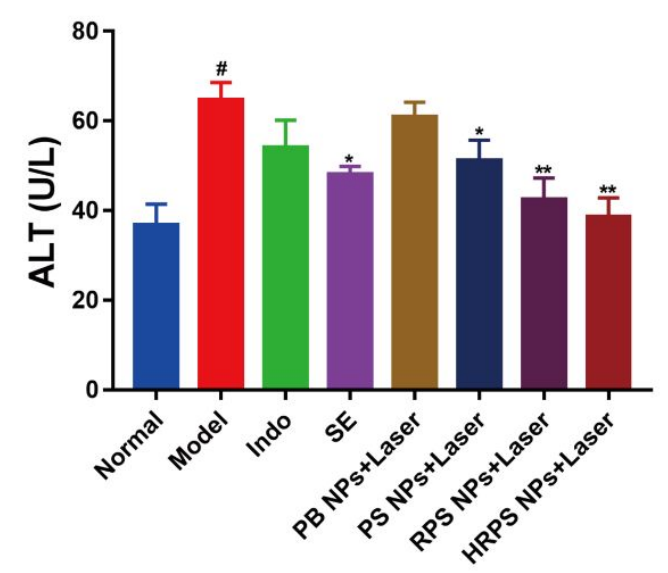

C

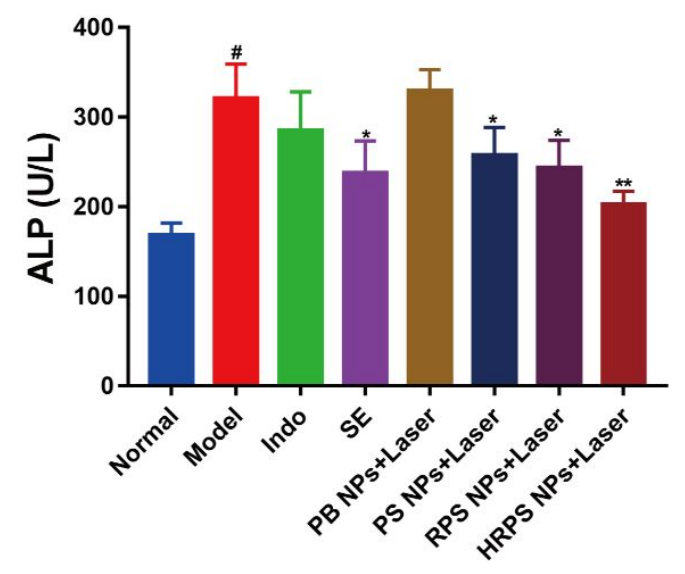

B

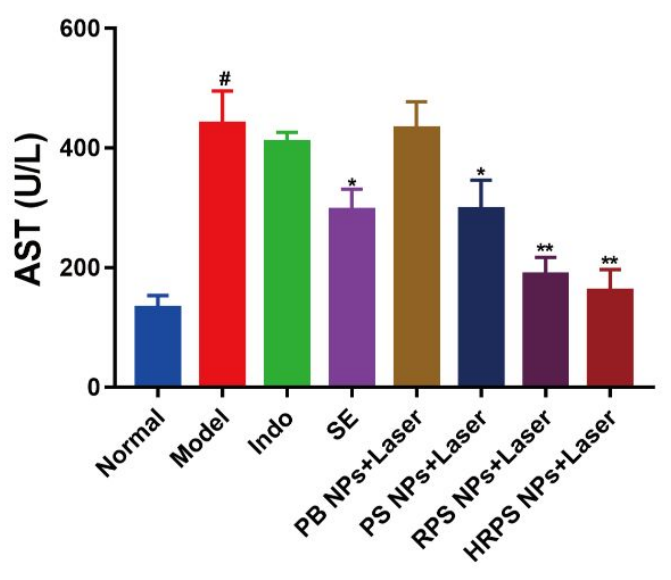

D

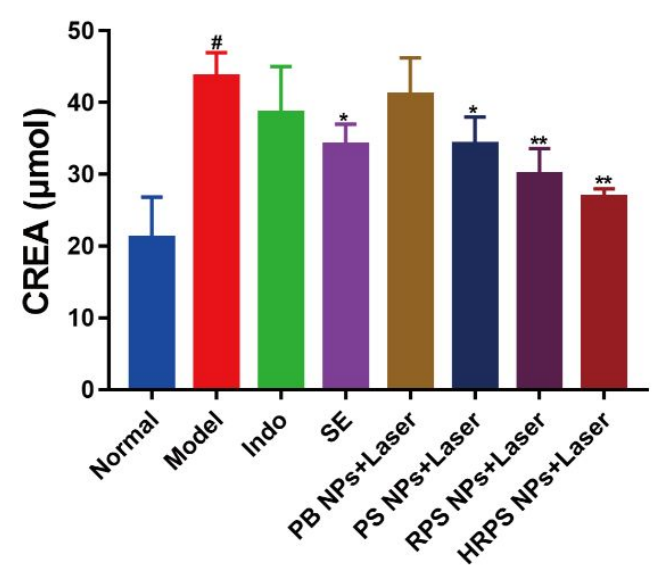

Figure S16 Hepatic and renal function tests of ALT (A), AST (B), ALP (C), CREA (D) in AIA rat blood after intravenous injection of saline, indomethacin, PB NPs, SE, PS NPs, RPS NPs, and HRPS NPs with $808 \mathrm{~nm}$ laser for day $31^{\mathrm{st}}\left(1.0 \mathrm{~W} / \mathrm{cm}^{2}\right) \mathrm{n}=6$. 


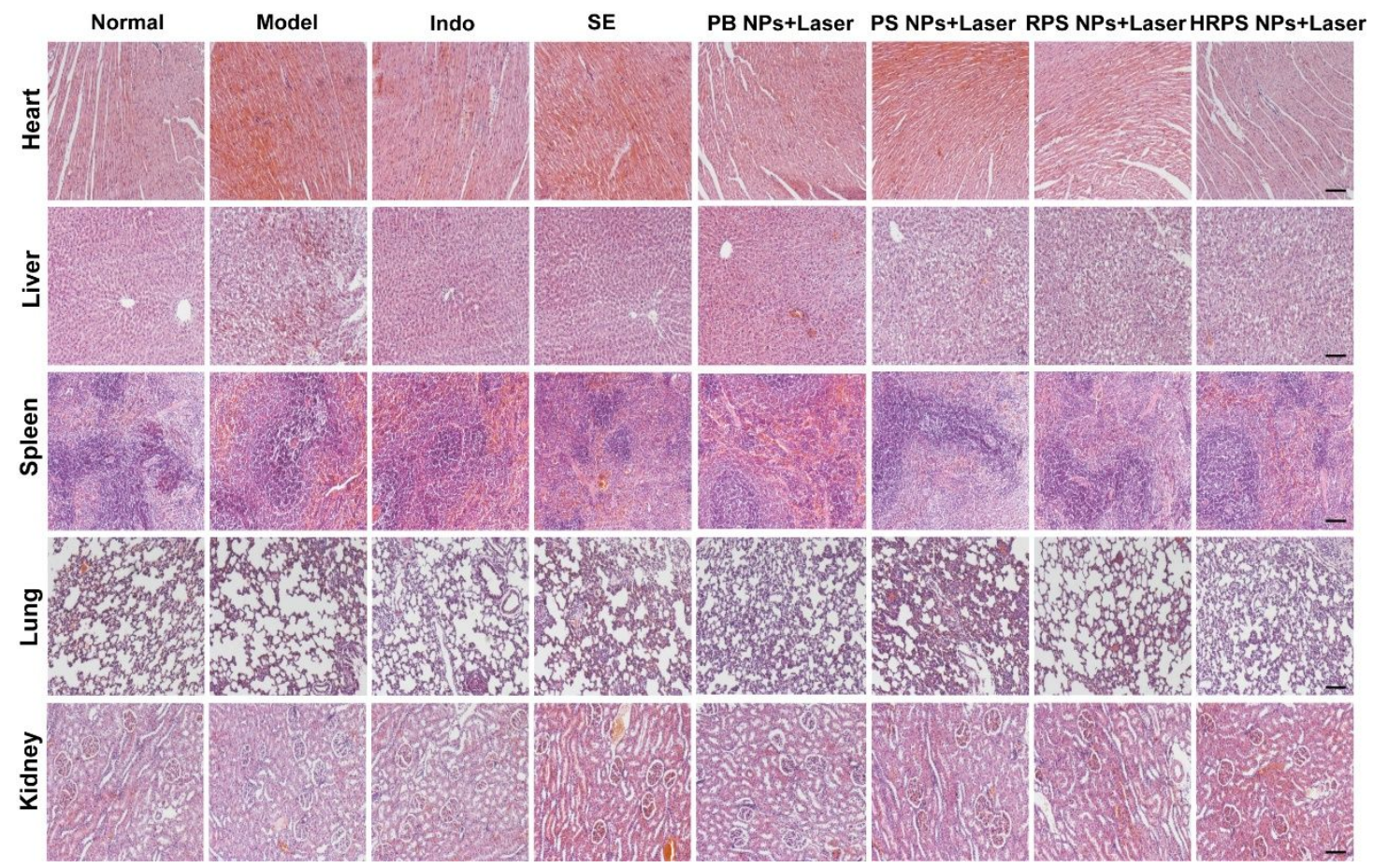

Figure S17 Biosafety assay of HRPS NPs in vivo. Histological sections of heart, liver, spleen, lung, and kidney tissues (H\&E staining) of rat treated with saline, indomethacin, PB NPs, SE, PS NPs, RPS NPs, and HRPS NPs with $808 \mathrm{~nm}$ laser for $30 \mathrm{~d}\left(1.0 \mathrm{~W} / \mathrm{cm}^{2}\right)(\mathrm{n}=6)$. Scale bar, $50 \mu \mathrm{m}$. Data presented as means $\pm \mathrm{SD}$. 
Table S1 Anti-RA compounds isolated from xuetong

\begin{tabular}{|c|c|c|c|c|c|c|}
\hline No & Compound & $\begin{array}{c}\text { Molecular } \\
\text { formula }\end{array}$ & $\begin{array}{c}\text { Molecular } \\
\text { weight }\end{array}$ & $\begin{array}{l}\text { Compound } \\
\text { type }\end{array}$ & $\mathrm{IC}_{50}(\boldsymbol{\mu M})$ & Structure \\
\hline 1 & Heteroclitalactone A & $\mathrm{C}_{32} \mathrm{H}_{46} \mathrm{O}_{6}$ & 526.32889 & Triterpenoid & 26.34 & Figure S1. \\
\hline 2 & Heteroclic acid & $\mathrm{C}_{32} \mathrm{H}_{48} \mathrm{O}_{5}$ & 512.3496 & Triterpenoid & 28.52 & Figure S1. \\
\hline 3 & Cycloartenone & $\mathrm{C}_{30} \mathrm{H}_{48} \mathrm{O}$ & 424.37 & Triterpenoid & $>30$ & Figure S1. \\
\hline 4 & Heteroclitalignan B & $\mathrm{C}_{31} \mathrm{H}_{38} \mathrm{O}_{11}$ & 586.2414 & Lignan & 27.91 & Figure S1. \\
\hline 5 & Kadsurarin & $\mathrm{C}_{30} \mathrm{H}_{36} \mathrm{O}_{11}$ & 572.2258 & Lignan & $>30$ & Figure S1. \\
\hline 6 & Heteroclitalactone F & $\mathrm{C}_{31} \mathrm{H}_{46} \mathrm{O}_{4}$ & 482.3391 & Triterpenoid & $>30$ & Figure S1. \\
\hline 7 & Schisandronic acid & $\mathrm{C}_{30} \mathrm{H}_{46} \mathrm{O}_{3}$ & 454.3447 & Triterpenoid & $>30$ & Figure S1. \\
\hline 8 & Meso-dihydroguaiaretic acid & $\mathrm{C}_{20} \mathrm{H}_{26} \mathrm{O}_{4}$ & 330.1831 & Lignan & $>30$ & Figure S1. \\
\hline 9 & Heteroclitalactone B & $\mathrm{C}_{33} \mathrm{H}_{48} \mathrm{O}_{6}$ & 540.3451 & Triterpenoid & $>30$ & Figure S1. \\
\hline 10 & Heteroclitalactone $\mathrm{C}$ & $\mathrm{C}_{34} \mathrm{H}_{50} \mathrm{O}_{6}$ & 554.3607 & Triterpenoid & $>30$ & Figure S1. \\
\hline 11 & Heteroclitalignan A & $\mathrm{C}_{31} \mathrm{H}_{32} \mathrm{O}_{11}$ & 580.1945 & Lignan & $>30$ & Figure S1. \\
\hline 12 & Heteroclitalactone I & $\mathrm{C}_{32} \mathrm{H}_{40} \mathrm{O}_{8}$ & 552.2723 & Triterpenoid & $>30$ & Figure S1. \\
\hline 13 & $\begin{array}{c}\text { 6-hydroxyhinokinin-6-O- } \beta \text {-D- } \\
\text { Glucopyranoside }\end{array}$ & $\mathrm{C}_{26} \mathrm{H}_{28} \mathrm{O}_{12}$ & 532.1581 & Lignan & $>30$ & Figure S1. \\
\hline 14 & Heteroclitalactone $\mathrm{H}$ & $\mathrm{C}_{32} \mathrm{H}_{40} \mathrm{O}_{7}$ & 536.2774 & Triterpenoid & 18.72 & Figure S1. \\
\hline 15 & Heteroclitalactone $\mathrm{G}$ & $\mathrm{C}_{32} \mathrm{H}_{40} \mathrm{O}_{6}$ & 520.2825 & Triterpenoid & 22.73 & Figure S1. \\
\hline 16 & Kadsulignan E & $\mathrm{C}_{31} \mathrm{H}_{30} \mathrm{O}_{11}$ & 578.1788 & Lignan & & Figure S1. \\
\hline & (8R,9S,22R)-3-Ethoxy-3-oxo-9,19-cyclo-3,4- & & & & 17.25 & Figure S1. \\
\hline 17 & secolanosta-4(28),24-dien-26-oic Acid 22,26- & $\mathrm{C}_{32} \mathrm{H}_{48} \mathrm{O}_{4}$ & 496.3553 & Triterpenoid & & \\
\hline
\end{tabular}


(8R,9S,22R)-3-Ethoxy-3-oxo-9, 19-cyclo-3,4-

$\mathrm{C}_{32} \mathrm{H}_{48} \mathrm{O}_{4} \quad 496.3553$

\section{Lactone}

Heteroclitalactone $\mathrm{J}$

$\mathrm{C}_{34} \mathrm{H}_{42} \mathrm{O}$

594.2829

Heteroclitalactone D

Schisanlactone B

Nigranoic acid

Heteroclitalactone E

Xuetongsu (SE)

6-Hydroxyhinokinin

Heteroclitalactone L d-epigalbacin

Changnanic acid

Xuetongdilactone A

Xuetongdilactone B

Xuetongdilactone $\mathrm{C}$

Xuetongdilactone D

Xuetongdilactone $\mathrm{F}$

Xuetonglactones D

Xuetongsu A

$\mathrm{C}_{32} \mathrm{H}_{42} \mathrm{O}_{6}$

522.2981

$\mathrm{C}_{30} \mathrm{H}_{42} \mathrm{O}_{4} \quad 466.3083$

$\mathrm{C}_{30} \mathrm{H}_{46} \mathrm{O}_{4} \quad 470.3391$

$\mathrm{C}_{32} \mathrm{H}_{40} \mathrm{O}_{7} \quad 536.2774$

$\mathrm{C}_{30} \mathrm{H}_{44} \mathrm{O}_{4} \quad 468.3240$

$\mathrm{C}_{20} \mathrm{H}_{18} \mathrm{O}_{7} \quad 370.1053$

$\mathrm{C}_{32} \mathrm{H}_{42} \mathrm{O}_{7} \quad 538.2931$

$\mathrm{C}_{20} \mathrm{H}_{20} \mathrm{O}_{5} \quad 340.1311$

$\mathrm{C}_{30} \mathrm{H}_{44} \mathrm{O}_{4} \quad 468.3240$

$\mathrm{C}_{32} \mathrm{H}_{46} \mathrm{O}_{8} \quad 558.3193$

$\mathrm{C}_{32} \mathrm{H}_{46} \mathrm{O}_{8} \quad 558.3193$

$\mathrm{C}_{32} \mathrm{H}_{44} \mathrm{O}_{8} \quad 556.3036$

$\mathrm{C}_{35} \mathrm{H}_{44} \mathrm{O}_{12} \quad 656.2832$

$\mathrm{C}_{28} \mathrm{H}_{36} \mathrm{O}_{11} \quad 548.2258$

$\mathrm{C}_{32} \mathrm{H}_{42} \mathrm{O}_{8} \quad 554.2880$

$\mathrm{C}_{32} \mathrm{H}_{40} \mathrm{O}_{7} \quad 536.2774$

Triterpenoid

Figure S1.

$\begin{array}{ccl}\text { Lignan } & >30 & \text { Figure S2. } \\ \text { Lignan } & >30 & \text { Figure S2. } \\ \text { Triterpenoid } & >30 & \text { Figure S2. } \\ \text { Triterpenoid } & 22.38 & \text { Figure S2. }\end{array}$

$\begin{array}{lll}\text { Triterpenoid } & 22.38 & \text { Figure S2. }\end{array}$

Triterpenoid $\quad 10.41 \quad$ Figure S2.

Triterpenoid $>30 \quad$ Figure S2.

Triterpenoid $\quad 18.73 \quad$ Figure S2.

Triterpenoid $\quad 9.12 \quad$ Figure S2.

Lignan $>30$

Triterpenoid $\quad 22.39$

Triterpenoid $>30$

Triterpenoid $>30$

Triterpenoid $>30$

Triterpenoid $>30$

Triterpenoid $>30$

Triterpenoid $>30$

Triterpenoid $>30$

Triterpenoid $>30$

Triterpenoid $>30$ 


\begin{tabular}{|c|c|c|c|c|c|c|}
\hline 40 & Xuetongsu B & $\mathrm{C}_{32} \mathrm{H}_{40} \mathrm{O}_{8}$ & 552.2723 & Triterpenoid & $>30$ & Figure S2. \\
\hline 41 & Xuetongsu C & $\mathrm{C}_{32} \mathrm{H}_{40} \mathrm{O}_{8}$ & 552.2723 & Triterpenoid & 19.23 & Figure S3. \\
\hline 42 & Xuetonglactones B & $\mathrm{C}_{32} \mathrm{H}_{42} \mathrm{O}_{7}$ & 538.2931 & Triterpenoid & 18.85 & Figure S3. \\
\hline 43 & Xuetongsu D & $\mathrm{C}_{32} \mathrm{H}_{46} \mathrm{O}_{7}$ & 542.3244 & Triterpenoid & 19.73 & Figure S3. \\
\hline 44 & Xuetongsu F & $\mathrm{C}_{30} \mathrm{H}_{44} \mathrm{O}_{4}$ & 468.3240 & Triterpenoid & 24.72 & Figure S3. \\
\hline 45 & Xuetongsu E & $\mathrm{C}_{33} \mathrm{H}_{48} \mathrm{O}_{6}$ & 540.3451 & Triterpenoid & $>30$ & Figure S3. \\
\hline 46 & CL-14 & $\mathrm{C}_{35} \mathrm{H}_{44} \mathrm{O}_{12}$ & 656.2832 & Triterpenoid & $>30$ & Figure S3. \\
\hline 47 & CL-15 & $\mathrm{C}_{29} \mathrm{H}_{40} \mathrm{O}_{8}$ & 516.2723 & Triterpenoid & $>30$ & Figure S3. \\
\hline 48 & Polysperlactone B & $\mathrm{C}_{32} \mathrm{H}_{46} \mathrm{O}_{6}$ & 526.3294 & Triterpenoid & 18.44 & Figure S3. \\
\hline 49 & Heteroclitalactone $\mathrm{K}$ & $\mathrm{C}_{32} \mathrm{H}_{38} \mathrm{O}_{8}$ & 550.2567 & Triterpenoid & 26.19 & Figure S3. \\
\hline 50 & Kadsuphilactone B & $\mathrm{C}_{30} \mathrm{H}_{42} \mathrm{O}_{5}$ & 482.3032 & Triterpenoid & 17.71 & Figure S3. \\
\hline 51 & $6 \alpha, 9 \alpha, 15$-trihydroxycadinan-4-en-3-one & $\mathrm{C}_{15} \mathrm{H}_{22} \mathrm{O}_{4}$ & 266.1518 & $\begin{array}{c}\text { Sesquiterpeno } \\
\text { id }\end{array}$ & 11.05 & Figure S3. \\
\hline 52 & (-)-3,10,11,12-tetrahydroxy-calamenene & $\mathrm{C}_{15} \mathrm{H}_{22} \mathrm{O}_{4}$ & 266.1518 & $\begin{array}{c}\text { Sesquiterpeno } \\
\text { id }\end{array}$ & 17.42 & Figure S3. \\
\hline 53 & (+)-3,11,12-trihydroxycalamenene & $\mathrm{C}_{15} \mathrm{H}_{22} \mathrm{O}_{3}$ & 250.1569 & $\begin{array}{c}\text { Sesquiterpeno } \\
\text { id }\end{array}$ & 17.72 & Figure S3. \\
\hline 54 & CL-25 & $\mathrm{C}_{16} \mathrm{H}_{20} \mathrm{O}_{5}$ & 292.1311 & $\begin{array}{c}\text { Sesquiterpeno } \\
\text { id }\end{array}$ & 16.80 & Figure S3. \\
\hline 55 & $6 \alpha, 9 \alpha$-dihydroxycadinan-4-en-3-one & $\mathrm{C}_{15} \mathrm{H}_{22} \mathrm{O}_{3}$ & 250.1569 & $\begin{array}{c}\text { Sesquiterpeno } \\
\text { id }\end{array}$ & 11.05 & Figure S3. \\
\hline 56 & Cryptomeridiol & $\mathrm{C}_{15} \mathrm{H}_{28} \mathrm{O}_{2}$ & 240.2089 & $\begin{array}{c}\text { Sesquiterpeno } \\
\text { id }\end{array}$ & 16.15 & Figure S3. \\
\hline 57 & Kadsulignan & $\mathrm{C}_{31} \mathrm{H}_{30} \mathrm{O}_{11}$ & 578.1788 & Lignan & $>30$ & Figure S3. \\
\hline 58 & Schizandriside & $\mathrm{C}_{25} \mathrm{H}_{32} \mathrm{O}_{10}$ & 492.1995 & Lignan & 16.57 & Figure S3. \\
\hline 59 & (+)-Isolariciresinol & $\mathrm{C}_{20} \mathrm{H}_{24} \mathrm{O}_{6}$ & 360.1573 & Lignan & $>30$ & Figure S3. \\
\hline
\end{tabular}




\begin{tabular}{|c|c|c|c|c|c|c|}
\hline 60 & Rubriflosides A & $\mathrm{C}_{26} \mathrm{H}_{28} \mathrm{O}_{12}$ & 532.1581 & Lignan & $>30$ & Figure S3. \\
\hline 61 & Lariciresinol & $\mathrm{C}_{20} \mathrm{H}_{24} \mathrm{O}_{6}$ & 360.1573 & Lignan & $>30$ & Figure S4. \\
\hline 62 & Pinoresinol & $\mathrm{C}_{22} \mathrm{H}_{26} \mathrm{O}_{6}$ & 386.1729 & Lignan & $>30$ & Figure S4. \\
\hline 63 & Medioresinol & $\mathrm{C}_{23} \mathrm{H}_{28} \mathrm{O}_{7}$ & 416.1835 & Lignan & $>30$ & Figure S4. \\
\hline 64 & Syringaresinol & $\mathrm{C}_{24} \mathrm{H}_{30} \mathrm{O}_{8}$ & 446.1941 & Lignan & $>30$ & Figure S4. \\
\hline 65 & Dihydrodehydrodiconiferylalcohol & $\mathrm{C}_{26} \mathrm{H}_{36} \mathrm{O}_{12}$ & 540.2207 & Lignan & $>30$ & Figure S4. \\
\hline 66 & $\begin{array}{c}\text { 7S, 8S-erythro-4, 9, 9'-trihydroxy-3, 3'- } \\
\text { dimethoxy-8-O-4'-neolignan-7-O-D } \\
\text { glucopyranoside }\end{array}$ & $\mathrm{C}_{26} \mathrm{H}_{36} \mathrm{O}_{12}$ & 540.2207 & Lignan & $>30$ & Figure S4. \\
\hline 67 & $\begin{array}{c}\text { 7S, 8R-erythro-4, 9, 9'-trihydroxy-3, 3'- } \\
\text { dimethoxy-8-O-4'-neolignan-7-O-D- } \\
\text { Glucopyranoside }\end{array}$ & $\mathrm{C}_{20} \mathrm{H}_{24} \mathrm{O}_{6}$ & 360.1573 & Lignan & $>30$ & Figure S4. \\
\hline 68 & Coumarinlignan & $\mathrm{C}_{20} \mathrm{H}_{16} \mathrm{O}_{7}$ & 368.0896 & Lignan & $>30$ & Figure S4. \\
\hline 69 & Cytochalasin $\mathrm{H}$ & $\mathrm{C}_{30} \mathrm{H}_{39} \mathrm{NO}_{5}$ & 493.2828 & Alkaloid & 13.15 & Figure S4. \\
\hline 70 & CL-41 & $\mathrm{C}_{20} \mathrm{H}_{18} \mathrm{O}_{8}$ & 386.1002 & Flavone & 14.28 & Figure S4. \\
\hline 71 & 3,4,5,7-Tetrahydroxyflavone,luteolin & $\mathrm{C}_{15} \mathrm{H}_{10} \mathrm{O}_{6}$ & 286.0477 & Flavone & 16.79 & Figure S4. \\
\hline 72 & Quercetin & $\mathrm{C}_{15} \mathrm{H}_{10} \mathrm{O}_{7}$ & 302.0427 & Flavone & $>30$ & Figure S4. \\
\hline 73 & 3',4',5,6,7,8-Hexamethoxyflavone, Nobiletin & $\mathrm{C}_{21} \mathrm{H}_{22} \mathrm{O}_{8}$ & 402.1315 & Flavone & $>30$ & Figure S4. \\
\hline 74 & Isomucronulatol & $\mathrm{C}_{17} \mathrm{H}_{18} \mathrm{O}_{5}$ & 302.32 & Flavone & $>30$ & Figure S4. \\
\hline 75 & & $\mathrm{C}_{30} \mathrm{H}_{50} \mathrm{O}$ & 426.729 & Flavone & $>30$ & Figure S4. \\
\hline 76 & $\begin{array}{l}\text { 1,2,3,4-tetrahydro-7-hydroxy-1-(4-hydroxy-3- } \\
\text { methoxyphenyl)-6-methoxy-2,3-Naphthale }\end{array}$ & $\mathrm{C}_{20} \mathrm{H}_{24} \mathrm{O}_{6}$ & 360.1573 & Lignan & $>30$ & Figure S4. \\
\hline 77 & Burselignan & $\mathrm{C}_{20} \mathrm{H}_{24} \mathrm{O}_{6}$ & 360.1573 & Lignan & $>30$ & Figure S4. \\
\hline 78 & $\beta$-sitosterol & $\mathrm{C}_{29} \mathrm{H}_{50} \mathrm{O}$ & 414.71 & Lignan & $>30$ & Figure S4. \\
\hline 79 & Schisanlactone c & $\mathrm{C}_{33} \mathrm{H}_{44} \mathrm{O}_{6}$ & 536.3138 & Triterpenoid & $>30$ & Figure S4. \\
\hline 80 & Galgarain & $\mathrm{C}_{22} \mathrm{H}_{28} \mathrm{O}_{5}$ & 372.1973 & Lignan & $>30$ & Figure S4. \\
\hline
\end{tabular}


Table S2 Differential metabolites between model and normal groups, SE and model groups, HRPS

NPs and model groups under positive and negative iron model.

\begin{tabular}{cccccc}
\hline Mode & Comparable & All & Differentia & Upregulated & Downregulate \\
& groups & metabolites & $\mathbf{l}$ & metabolites & d metabolites \\
& & & metabolites & & \\
\hline Positive & Model/Normal & 11080 & 770 & 192 & 578 \\
Negative & Model/Normal & 8302 & 1226 & 544 & 682 \\
Positive & SE/Model & 11080 & 483 & 353 & 130 \\
Negative & SE/Model & 8302 & 1106 & 643 & 463 \\
Positive & HRPS NPs/Model & 11080 & 5055 & 1542 & 3513 \\
Negative & HRPS NPs/Model & 8302 & 3140 & 1366 & 1774 \\
\hline
\end{tabular}


Method S1 HPLC condition.

The HPLC analysis was briefly performed on an Agilent 1260 system equipped with a G1311C quaternary pumps, a G1329B sampler, a G1316A column compartment and a G4212B diode-array detector. An Agilent TC-C18 $(5 \mu \mathrm{m}, 150 \mathrm{~mm} \times 4.6 \mathrm{~mm})$ column was applied for the determination of the six constituents. The aqueous solution containing $0.1 \%$ phosphoric acid and $100 \%$ acetonitrile was used as the mobile phase. The gradient elution was as follows $0-30 \mathrm{~min}, 65-85 \%$ acetonitrile. The flow rate, column temperature, injection volume, and detection wavelength were optimized to be $1 \mathrm{~mL} / \mathrm{min}^{1}, 25^{\circ} \mathrm{C}, 5 \mu \mathrm{L}$, and $210 \mathrm{~nm}$, respectively. Data acquisition was performed on Agilent Chem Station software.

Method S2 Immunohistochemical and immunofluorescence assay.

The rats were anaesthetized and sacrificed on day 31 st and the paws between knee joints and distal phalanx were removed for immunohistochemical and immunofluorescence analysis after routine fixation, decalcification, and paraffin embedding of tissue. Tissue sections were sequentially incubated with specific antibodies directed against murine TNF- $\alpha$, IL-6, IL-23, and IL-17, followed by the appropriate secondary antibodies. Immunofluorescent staining of rat paw tissues from all treatment groups was also fixed and embedded in paraffin for microtome sectioning and immunofluorescence staining. After deparaffinization, the tissue sections (4 $\mu \mathrm{m}$ thick) were subjected to antigen retrieval (EnVision ${ }^{\mathrm{TM}}$ FLEX Target Retrieval Solution, High pH $(50 \times)$ ). Anti-TNF- $\alpha$, IL-6, IL-23, and IL-17 were used in the analysis. The coverslips were then mounted 
with FluorSave ${ }^{\mathrm{TM}}$ mounting media (Calbiochem, San Diego, CA, USA) for fluorescence imaging. All tissue samples of rat paws were counterstained with hematoxylin. After staining, expression of the different markers in the paw tissue of rats was scored semiquantitatively according to the staining and expression of different antibody markers in paw tissue, and the average score was calculated. A score of 0 indicates minimal expression, 1 indicates mild expression, 2 indicates moderate expression, and 3 indicates abundant marker expression. Minor differences between observers were resolved through mutual consultation.

Method S3 Metabolite extraction and metabonomic analysis of serum.

All samples were acquired by the LC - MS system followed by given method. Firstly, all chromatographic separations were performed using an ultra-performance liquid chromatography (UPLC) system (SCIEX, UK). An ACQUITY UPLC T3 column (100mm*2.1mm, $1.8 \mu \mathrm{m}$, Waters, UK) was used for the reversed phase separation. The column oven was maintained at $35^{\circ} \mathrm{C}$. The flow rate was $0.4 \mathrm{~mL} / \mathrm{min}^{1}$ and the mobile phase consisted of solvent $\mathrm{A}$ (water, $0.1 \%$ formic acid) and solvent B (Acetonitrile, $0.1 \%$ formic acid). Gradient elution conditions were set as follows: 0 0.5 $\min , 5 \% \mathrm{~B}$; $0.5 \sim 7 \mathrm{~min}, 5 \%$ to $100 \% \mathrm{~B}$; 7 8 $\mathrm{min}, 100 \% \mathrm{~B} ; 8 \sim 8.1 \mathrm{~min}, 100 \%$ to $5 \% \mathrm{~B} ; 8.1 \sim 10$ $\min , 5 \% \mathrm{~B}$. The injection volume for each sample was $4 \mu \mathrm{L}$.

A high-resolution tandem mass spectrometer TripleTOF5600plus (SCIEX, UK) was used to detect metabolites eluted form the column. The Q-TOF was operated in both positive and negative ion modes. The curtain gas was set 30 PSI, Ion source gas1 was set 60 PSI, Ion source gas2 was set $60 \mathrm{PSI}$, and an interface heater temperature was $650^{\circ} \mathrm{C}$. For positive ion mode, the Ionspray voltage floating was set at $5000 \mathrm{~V}$, respectively. For negative ion mode, the Ionspray voltage floating was set at $-4500 \mathrm{~V}$, respectively. The mass spectrometry data were acquired in IDA mode. The TOF mass range was from 60 to $1200 \mathrm{Da}$. The survey scans were acquired in $150 \mathrm{~ms}$ and as many as 12 product 
ion scans were collected if exceeding a threshold of 100 counts per second (counts/s) and with a $1+$ charge-state. Total cycle time was fixed to $0.56 \mathrm{~s}$. Four-time bins were summed for each scan at a pulser frequency value of $11 \mathrm{kHz}$ through monitoring of the $40 \mathrm{GHz}$ multichannel TDC detector with four-anode/channel detection. Dynamic exclusion was set for $4 \mathrm{~s}$. During the acquisition, the mass accuracy was calibrated every 20 samples. Furthermore, in order to evaluate the stability of the LC-MS during the whole acquisition, a quality control sample (Pool of all samples) was acquired after every 10 samples. 